\title{
Illicit financial flows and the provision of child and maternal health services in low- and middle-income countries
}

\author{
Bienvenido Ortega* ${ }^{*}$, Jesús Sanjuán and Antonio Casquero
}

\begin{abstract}
Background: Illicit financial flows (IFFs) drain domestic resources with harmful social effects, especially in countries which are too poor to mobilise the revenues required to finance the provision of essential public goods and services. In this context, this article empirically examined the association between IFFs and the provision of essential health services in low- and middle-income countries.

Methods: Firstly, a set of indicators was selected to represent the overall coverage of essential health services at the country level. Next, a linear multivariate regression model was specified and estimated for each indicator using cross-sectional data for 72 countries for the period 2008-2013.

Results: After controlling for other relevant factors, the main result of the regression analysis was that an annual 1 percentage point (p.p.) increase in the ratio of IFFs to total trade was associated with a 0.46 p.p. decrease in the level of family planning coverage, a 0.31 p.p. decrease in the percentage of women receiving antenatal care, and a 0.32 p.p. decrease in the level of child vaccination coverage rates.

Conclusions: These findings suggest that, for the whole sample of countries considered, at least 3.9 million women and 190,000 children may not receive these basic health care interventions in the future as a consequence of a 1 p.p. increase in the ratio of IFFs to total trade. Moreover, given that family planning, reproductive health, and child immunisation are foundational components of health and long-term development in poor countries, the findings show that IFFs could be undermining the achievement of the 2030 Agenda for Sustainable Development.
\end{abstract}

Keywords: Illicit financial flows, Health financing, Essential health services coverage, Family planning, Antenatal care, Child immunisation, Sustainable development goals, Low- and middle-income countries

\section{Background}

Despite recent progress in health provision in many lowand middle-income countries (LMICs), the capacity of their health systems remains severely depleted. There is persistent exclusion and lack of access to basic quality services for large sectors of the population. It is well known that there are imbalances in access to essential services among regions and countries, between the

\footnotetext{
* Correspondence: ortega@uma.es

Departamento de Economía Aplicada (Estructura Económica), Universidad de Málaga, Campus El Ejido, 29071 Málaga, Spain
}

urban, rural, and hard-to-reach areas, inadequate health infrastructures across countries, and shortages of human health resources [1]. In addition, such disparities follow economic lines, with access being at its lowest in lowincome countries and in the most vulnerable populations. In these areas and populations, many people have insufficient money to pay for vital services or for transportation to reach them, or they are unable to take time away from their families, work, or school to use these services, even when they are available [2]. In addition, many worthy causes compete for limited public

(C) The Author(s). 2020 Open Access This article is licensed under a Creative Commons Attribution 4.0 International License, which permits use, sharing, adaptation, distribution and reproduction in any medium or format, as long as you give appropriate credit to the original author(s) and the source, provide a link to the Creative Commons licence, and indicate if changes were made. The images or other third party material in this article are included in the article's Creative Commons licence, unless indicated otherwise in a credit line to the material. If material is not included in the article's Creative Commons licence and your intended use is not permitted by statutory regulation or exceeds the permitted use, you will need to obtain permission directly from the copyright holder. To view a copy of this licence, visit http://creativecommons.org/licenses/by/4.0/ The Creative Commons Public Domain Dedication waiver (http://creativecommons.org/publicdomain/zero/1.0/) applies to the data made available in this article, unless otherwise stated in a credit line to the data. 
resources in LMICs, such that setting priorities for health is of special relevance to maximize the impact of investments.

The economic and social consequences of poor health service coverage and outcomes on families and communities are significant. Relevant social benefits can be gained by addressing the most vulnerable groups, such as children and mothers. For example, political will, as well as the prioritization of maternal health in budgeting, has driven progress in addressing maternal and newborn health issues in some African countries, such as Benin, Cameroon, and Uganda [3]. In this regard, attention must be paid to the fact that crucial health-care interventions, such as attending antenatal care and having a skilled health worker at the time of delivery, can generally prevent women from dying of pregnancy-related causes in developing countries [4]. Health issues are also intricately connected to the economic and developmental prospects of women and girls [5]; such issues are central to progress in global development efforts [6]. In this regard, the ancillary health, economic, and development benefits of family programs would be substantial. Moreover, reducing unmet family planning needs has unequivocally saved lives and money [1,7]. The promotion of family planning in LMICs has the potential to reduce poverty and hunger and to prevent $30 \%$ of all maternal deaths and nearly $10 \%$ of childhood deaths [8]. Moreover, the additional immunisation costs decrease over time as population size decreases [9]. The United Nations [10] has estimated that, for "every dollar spent in family planning, between two and six dollars can be saved in interventions aimed at achieving other development goals".

In this context, the Third United Nations (UN) Financing for Development Conference adopted the Addis Ababa Action Agenda (AAAA). Although this agenda involves boosting the financing of Sustainable Development Goals (SDGs), in many LMICs weak health systems are functioning with meagre and inequitably distributed resources [11]. This situation has arisen mainly because these countries have limited access to international financial markets, are particularly vulnerable to macroeconomic shocks, and frequently rely on volatile external financing sources, such as official development assistance (ODA). Thus, in addition to support from the international community, domestic resource mobilisation is the only sustainable strategy available to LMICs to finance their basic healthcare services [12]. However, substantial public revenues are lost due to the existence of illicit financial flows (IFFs), particularly in LMICs. These financial flows are cross-border transfers of funds that are illegally earned, transferred, or utilized. They are the main driving force behind the net drain of domestic financial resources from most countries in developing areas. Furthermore, these IFFs from developing countries steadily increased to reach US\$ 1.1 trillion in 2013, exceeding the combined total ODA and foreign direct investment (FDI) received by these economies [13]. For example, to mention two very different and relevant cases, Togo lost approximately $34 \%$ of its GDP per year in the period 2008-2013 through illicit financial outflows, while Costa Rica lost an amount equivalent to $26 \%$ of its GDP. Moreover, in the case of Togo, the amount of resources lost through IFFs represents, on average, five times the total tax revenues in the period. In Costa Rica, the amount of IFFs was 2.8 times higher than the tax revenue managed by the central government within this period. Following Zucman [14], if we assume a rate of return of $5 \%$ for undeclared wealth and apply an average tax rate on investment incomes of $50 \%$ in the case of Togo and $58 \%$ in the case of Costa Rica (i.e. the average commercial tax rates in these countries according to the World Bank), the annual government's revenue losses due to IFFs are estimated to be 12 and $8 \%$ of total public revenues, respectively. Thus, these figures show both the enormous magnitude of IFFs in these countries and their potential damaging impact on the capacity of public budgets. In this regard, the case of Africa is noteworthy. According to the African Development Bank and Global Financial Integrity (GFI) [15], Africa lost between US\$ 1.2-1.3 trillion dollars over the period 1980-2009 through IFFs, an amount which is about four times Africa's total external debt. Indeed, in 2009, IFFs out of Africa were more than three times the amount of ODA received. As a global response to this problem, the World Bank has established analytical and operational approaches to strategically address IFFs as a core developmental issue [16].

Thus, although the magnitude of IFFs and their potential role in damaging the capacity of the state budget in LMICs is increasingly recognized, a few studies have found evidence for the effect of IFFs on the provision of public goods and services [17-19]. These studies are examples of the few research efforts that have attempted to provide quantitative studies that assess the relationships between IFFs and health services. On the one hand, O'Hare et al. [17] found that IFFs had a significant effect on achieving the fourth target of the millennium development goal (MDG) (i.e. to reduce the under-five mortality rate by two-thirds between 1990 and 2015) in Sub-Saharan Africa (SSA) countries. In addition, O'Hare et al. [18] provided evidence on the time needed for the SSA region countries to reach this target if national resources had been fully mobilized (i.e. in the absence of leaks, such as IFFs, corruption, and debt service). On the other hand, the negative effect of IFFs on infant immunization coverage rates in LMICs was analysed by Ortega et al. [19].

Given this background, the main aim of this article was to analyse the association between cross-country 
differences in the level of IFFs and current dissimilarities in the coverage of basic health services across countries. In this sense, this study contributes to the existing literature [17-19] in several ways. Firstly, it provides evidence on the negative association between the increase in IFFs and the provision of a representative set of essential health services, including those related to the health care of vulnerable populations (i.e. child and maternal health). Secondly, this study also shows that the potential negative effect of IFFs is not uniformly distributed across regions and health services. In particular, these negative associations were detected in regions such as SSA, the Middle East, and North Africa (MENA), and countries included in the Europe \& Central Asia (ECA) region.

The following section presents the analytical framework used and reviews the existing literature on the effects of IFFs on health development. Next, the data and the statistical methodology used in the empirical analysis are presented. Finally, the research findings are discussed and some conclusions are offered.

\section{Theoretical framework and related literature}

A strong revenue generating capacity is fundamental for a developing country to sustainably generate financing for its own development [20-22]. However, the use of public funds from domestic sources to finance health has stagnated in most LMICs, without evidence that domestic public financing has been replaced by private financing [23]. For this reason, the SDGs and the AAAA recognize the importance of mobilising domestic revenue to ensure the financing of the 2030 Agenda for Sustainable Development. Indeed, SDG Target 17.1 is to "strengthen domestic resource mobilization, including through international support to developing countries, to improve domestic capacity for tax and other revenue collection". Nevertheless, there is intense debate on the way to finance progress towards the health-related SDGs in LMICs. In many poor countries, the existence of a large informal sector (i.e., the part of the economy which escapes tax coverage) significantly reduces the governments' capacity to raise public revenues above the critical threshold of $15 \%$ of GDP, below which threshold countries have difficulty in funding basic state functions [16]. In addition, these difficulties are often aggravated during domestic resource collection processes. Poverty may increase if, for example, these resources are collected by increasing consumption taxes - which is the most likely source to be effective [24] — but without implementing specific policies to improve the situation of the poor. Thus, one of the greatest risks in setting an ambitious domestic resource mobilization agenda is that in the process governments will impoverish poor people even further [25]. In addition, international corporate tax competition and trade liberalisation have also diminished the states' capacity for domestic resource mobilisation [24].

On these grounds, the existence of IFFs is an issue that has received special attention within the policy coherence framework [26-28]. This issue has also been highlighted in the SDG 16.4: "By 2030, significantly reduce illicit financial and arms flows, strengthen the recovery and return of stolen assets, and combat all forms of organized crime" [29]. In fact, the WHO [30] stated that a country's capacity to raise and spend funds domestically will be further enhanced if the statements of intent made in Addis Ababa to make tax systems more efficient nationally are realized by implementing effective measures to reduce tax evasion and illicit tax flows globally. In this regard, it is important to recall that Ndikumana et al. [31] suggested that each additional dollar allocated to debt servicing means 29 cents less allocated to public health spending. O'Hare and Curtis [32] also studied deficiencies in healthcare financing in Malawi, showing that these financial shortages could be filled by corporate tax incentives and tax revenues foregone due to IFFs. Similarly, Mosselmans [33] showed that, if current spending patterns were maintained, the lives of 1.9 million children could be saved every year if the resources lost due to tax evasion were available to governments. These facts are in line with recent trends in global health financing that show that growth in public health spending is largely a consequence of economic growth and fiscal expansion rather than a consequence of governments giving priority to health [34]. In addition, it is important to note that the growing relevance of IFFs from developing countries is a mirror of severe institutional and governance difficulties. There is growing evidence that IFFs widen inequalities in multiple ways, help to preserve unequal power relationships, and further weaken already weak state institutions [35].

As shown in Fig. 1, IFFs may arise from a wide set of activities, such as corruption, criminal activities, transfer pricing, and trade misinvoicing. Although estimates of IFFs show that this phenomenon is widespread and highly persistent, people in developing countries are particularly hard hit, given that the quality (and scope) of the provision of public services could radically depend on the reduction of these illicit flows [36]. This is even more evident in environments in which international corporate tax competition has decreased the states' capacity for domestic resource mobilization ('races to the bottom'). For example, 'if the tax breaks had not been granted and the health budget increased by 10-fold, the effect of Ebola on Sierra Leone might have been avoided' [37].

From a broader perspective, IFFs lead to decreases in domestic resources, which influence consumption and reduce national savings and investment. As result of these losses of resources and tax revenues, as well as 


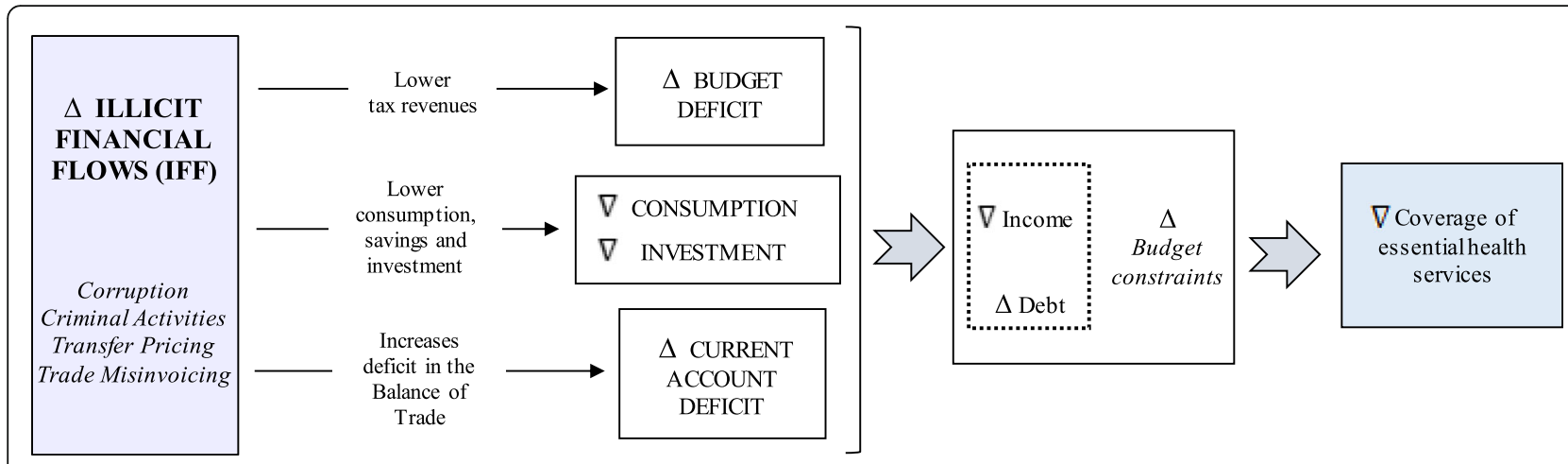

Fig. 1 How IFFs can reduce the provision of health services

pressures exerted on the budget, a second channel of IFFs arises in the form of budget deficits, which lead to less social spending (health, education, and infrastructure) for socially and economically disadvantaged population. Furthermore, in many developing countries, increased IFFs are accompanied by increased foreign borrowing (the so-called 'revolving door' syndrome) [31, 38-44]. The commitment to pay off this debt and the debt service charges reduce the capacity of governments to increase social spending. Thus, the relationship between debt and illicit flows forms a vicious cycle; as countries borrow more, capital flight accelerates as corrupt politicians and officials divert loans offshore. Thus, the existence of IFFs leads to external flow imbalances in the economy, reduces foreign reserves, and increases current account deficits. Furthermore, IFFs not only reduce countries' fiscal space but also promote inefficient public expenditures, thus increasing the cost and reducing the quality of the provision of public services.

Having drawn attention to these issues, it is relevant to note that the availability of additional government revenues has not always led to a commensurate increase in public investments in basic health services, as occurs in the case of aid fungibility for health in developing countries. This non-additionality of aid occurs when an increase in donor funding is associated with a proportionate decrease in government spending in health [45]. For example, ODA might relax the recipient government's budget constraint and eventually lose public resources that can be spent on health services, but also on other social or non-social expenditures. The process by which these extra resources may be displaced from basic health services to other priorities may occur at two stages throughout the budget allocation process: firstly, during negotiations between different ministries for resources from the general budget; and, secondly, during the health sector allocation of its own funds [46]. On the one hand, the final allocation of these resources might depend on both the bargaining power of the different ministries and the prevailing budgeting priorities during this process. In this regard, it is important to point out that these priorities may change during this process (e.g. because of unexpected changes in the country's macroeconomic and/or social context). This is especially evident in the case of fiscally constrained governments with a wide range of priorities in which these extra-resources may be invested. On the other hand, when it can be assumed that these extra resources will be fully invested in health, this does not imply that the entire additional funding will be invested on basic services. As a result of the availability of such additional financing, there could be circumstances in which government health priorities could shift from basic health services to secondary or even tertiary services. In addition, it can be assumed that the potential effect of the availability of additional resources on the provision of basic health services may be direct and/or induced or indirect. Regarding the indirect effect, it is important to note that government investments in other competing priorities may also have positive effects on health achievements. Such competing priorities may include education, especially in the case of female education, and some kinds of infrastructure investments (e.g. those related to water provision).

Finally, it is important to note that the main illicit capital flight comes from trade misinvoicing [47]. Trade misinvoicing is a form of customs and/or tax fraud involving exporters and importers deliberately misreporting the value, quantity, or nature of goods or services in a commercial transaction [48]. This issue has received increasing attention through the debates on IFFs, because trade misinvoicing continues to be used as a key mechanism to fuel IFFs from developing countries [49]. In fact, of the total annual illicit financial outflows in LMICs, close to $80 \%$ of the funds are moved offshore using trade misinvoicing [47]. This problem also motivated the UN Economic Commission for Africa (UNECA) and the African Union to establish a High Level Panel on Illicit Financial Flows from Africa. This panel estimated that trade misinvoicing, which is concentrated on a few products, is the reason for $\$ 50$ billion worth of illicit flows from Africa [50]. These estimated 
high levels of trade misinvoicing have played a key role in the decision to incorporate the issue of IFFs into the Sustainable Development Goals [51].

\section{Methods \\ Data}

The original database comprised data from 73 countries. However, no data were available on the variable of interest (IFF/Trade) for Sao Tome and Principe. For this reason, this country was not included in the regression analyses, although data exists for the dependent variables. Thus, this study used data for the available sample of 72 LMICs for the period 2008 to 2013. However, due to data availability constraints, a panel could not be constructed for all variables, as can be seen in Table A1 (see Additional file 1). This table provides information on the annual observations available for each country included in the original database. The table shows that there are three dependent variables (Antenatal Care, Hospital Beds, and Physicians) for which only one or two annual observations are available for most countries, and which do not always correspond to the same year within the period 2008-2013. For example, in the specific case of 'Antenatal care', 2010 was the year in which more crosssection observations were available within this period. For 2010, we only have information for 23 countries in the sample. Furthermore, in the case of 2008, we only have information for 12 countries in the sample. In addition, in most cases (47 countries), we have a pointin-time observation available within the period 20082013. For these reasons, the original data was transformed in order to obtain representative cross-sectional data points for the period. These cross-sectional data was obtained by 'period-averaging' the available data points in the sample. Thus, when a variable had more than one data point within the period in a country, the arithmetic mean of the available temporal observations for this variable was calculated to obtain a representative value for this country. However, for certain countries and variables, if just one temporal observation was available within the period (one point in time), it was considered to be the representative value for the entire period [52]. The literature shows that there could be additional reasons for using the 'period averaging method' when employing cross-section time series datasets. For example, when temporal data are very scattered across countries (with a profusion of missing data points), are potentially subject to measurement errors (especially when errors are non-random), and their levels do not fluctuate very much within the period considered (as is our case), then cross-sectional regressions based on period averages may be more effective than more sophisticated statistical models which employ pooled data or available full time series information [53]. Thus, the variables used, data imputation, country selection, and statistical approach employed were strongly constrained by data availability. Tables 1 and 2 show the variables included in the database and the list of countries, respectively.

The key variable used in this study was the ratio of IFFs to total trade in each country. Given that, by construction, the volume of IFFs in a country is strongly restricted by the quantity of financial flows originating from trade [54], the indicator of the relative importance of the IFFs used was calculated as a ratio of the IFFs to total trade (IFFT). On the other hand, a normalisation of IFFs in terms of GDP or population may give the misleading impression that, for large countries with relative high GDP and large population, the magnitude of IFFs is not a relevant issue. This is the case, for example, of Nigeria. It is well known that this country has a severe illicit financial outflow problem, but this country ranks low in the list of IFF/population ratios due to its large population [15, p. 27]. Another example is provided by the high levels of IFF/GDP in Vietnam (2.70\%) compared to Indonesia (0.90\%) in the period 2008-2013 (i.e. three times greater in the case of Vietnam). This ratio was a direct consequence of differences in the size of the GDP between these economies (i.e. the GDP of Indonesia is 5.3 times higher than that of Vietnam). However, these results do not reflect differences in the relevance of IFFs in these economies. For these reasons, it was considered that IFFT (i.e. how much money was transferred illicitly to foreign countries for each dollar traded), rather than IFF/GDP or IFF per capita, was an unbiased measure of the scale of this problem. Thus, the variable IFFT was obtained following the methods described in Ortega et al. [19], in which annual panel IFFT data for 56 low- and middle-income countries for the period 2002-13 were calculated.

In addition, key health activity coverage is a widely accepted indicator of progress toward improving health systems and achieving SDGs. Thus, following the proposal by Hogan et al. [55], a set of indicators that represent overall essential health services coverage was selected for analysis. These indicators included the following areas: reproductive, maternal, newborn, and child health; infectious diseases; non-communicable diseases; and service capacity. However, indicators related to the prevention and management of non-communicable diseases were excluded from the analysis due to the widespread scarcity of data. Figure 2 shows the final indicators selected, which are classified by category.

\section{Empirical model and estimation strategy}

The following cross-sectional model was used as a baseline specification to analyse the association between the relative size of IFFs and the selected indicators 
Table 1 Variables employed in the estimations

\begin{tabular}{|c|c|c|}
\hline Variable & Definition & Data source \\
\hline Family planning, coverage & $\begin{array}{l}\text { The percentage of total demand for family planning among married or in-union women aged 15- } \\
49 \text { years }\end{array}$ & $\begin{array}{l}\text { World Health } \\
\text { Organization }\end{array}$ \\
\hline Antenatal care, coverage & $\begin{array}{l}\text { Percentage of women attended at least once during pregnancy by skilled health personnel for } \\
\text { reasons related to pregnancy. }\end{array}$ & World Bank \\
\hline DTP3, coverage & $\begin{array}{l}\text { The percentage of 1-year-olds who have received three doses of combined diphtheria, tetanus tox- } \\
\text { oid and pertussis vaccine in a given year }\end{array}$ & $\begin{array}{l}\text { World Health } \\
\text { Organization }\end{array}$ \\
\hline Measles, coverage & $\begin{array}{l}\text { The percentage of children less than } 1 \text { year who have received at least one dose of measles- } \\
\text { containing vaccine in a given year }\end{array}$ & $\begin{array}{l}\text { World Health } \\
\text { Organization }\end{array}$ \\
\hline Tuberculosis, coverage & $\begin{array}{l}\text { Tuberculosis effective treatment }=\text { Case detection rate (all forms) } \cdot \text { Treatment success rate for all } \\
\text { new cases }\end{array}$ & $\begin{array}{l}\text { World Health } \\
\text { Organization }\end{array}$ \\
\hline Sanitation, Coverage & $\begin{array}{l}\text { Access to improved sanitation facilities refers to the percentage of the population with at least } \\
\text { adequate access to excreta disposal facilities ranging from simple but protected pit latrines to flush } \\
\text { toilets with a sewerage connection }\end{array}$ & $\begin{array}{l}\text { World Health } \\
\text { Organization }\end{array}$ \\
\hline Hospital beds & $\begin{array}{l}\text { Total number of beds per } 1000 \text { population. Hospital beds include inpatient beds available in public, } \\
\text { private, general, and specialized hospitals and rehabilitation centres }\end{array}$ & $\begin{array}{l}\text { World Health } \\
\text { Organization }\end{array}$ \\
\hline Physicians & Total number of physicians per 1000 population & $\begin{array}{l}\text { World Health } \\
\text { Organization }\end{array}$ \\
\hline IFF & $\begin{array}{l}\text { IFFS are illegal movements of money or capital in current US\$ from one country to another. The } \\
\text { illegal capital outflows stem from crime, corruption, tax evasion, and other illicit activity. Current US } \\
\$ \text {. }\end{array}$ & $\begin{array}{l}\text { Global Financial } \\
\text { Integrity }\end{array}$ \\
\hline Trade & Total trade, in current US\$ & $\begin{array}{l}\text { World Trade } \\
\text { Organization }\end{array}$ \\
\hline IFFT & (IFF / Trade) $\cdot 100$ & Authors \\
\hline GDPpC & GDP per capita, in constant 2011 international \$ & World Bank \\
\hline $\begin{array}{l}\text { GIR, 1st grade of primary } \\
\text { education, female }\end{array}$ & $\begin{array}{l}\text { Gross intake ratio in first grade of primary education is the number of new entrants in the first } \\
\text { grade of primary education regardless of age, expressed as a percentage of the population of the } \\
\text { official primary entrance age }\end{array}$ & United Nations \\
\hline Urban population & Percentage of people living in urban areas, as defined by national statistical offices & United Nations \\
\hline Births attended & Births attended by skilled health staff (\% of total) & World Bank \\
\hline$C P I$ & Corruption Perceptions Index, values from 0 (highly corrupt) to 10 (clean country) & $\begin{array}{l}\text { Transparency } \\
\text { International }\end{array}$ \\
\hline Density & Population density (people per $\mathrm{km}^{2}$ ) & United Nations \\
\hline Dependency & $\begin{array}{l}\text { Dependency ratio is the ratio (in \%) of dependents (people younger than } 15 \text { or older than } 64 \text { years) } \\
\text { to the working-age population (those aged 15-64 years). }\end{array}$ & World Bank \\
\hline Literacy & $\begin{array}{l}\text { Adult literacy rate is the percentage of people aged } 15 \text { years or more who can both read and write } \\
\text { with understanding a short simple statement about their everyday life. }\end{array}$ & United Nations \\
\hline $\begin{array}{l}\text { Labour force participation } \\
\text { rate, female }\end{array}$ & $\begin{array}{l}\text { The female labour force as a percentage of the total shows the extent to which women are active } \\
\text { in the labour force. Labour force comprises people aged } 15 \text { years or more who supply labour for } \\
\text { the production of goods and services during a specified period }\end{array}$ & World Bank \\
\hline Population & $\begin{array}{l}\text { Total population between the ages } 15 \text { to } 64 \text { as a percentage of the total population. Population is } \\
\text { based on the de facto definition of population, which counts all residents regardless of legal status } \\
\text { or citizenship. }\end{array}$ & United Nations \\
\hline EAP & EAP equals 1 for the countries that belong to the East Asia \& Pacific region, and equals 0 otherwise. & Authors \\
\hline ECA & $\begin{array}{l}\text { ECA equals } 1 \text { for the countries that belong to the Europe \& Central Asia region, and equals } 0 \\
\text { otherwise. }\end{array}$ & Authors \\
\hline$\angle A C$ & $\begin{array}{l}\text { LAC equals } 1 \text { for the countries that belong to the Latin America \& Caribbean region, and equals } 0 \\
\text { otherwise. }\end{array}$ & Authors \\
\hline MENA & $\begin{array}{l}\text { MENA equals } 1 \text { for the countries that belong to the Middle East \& North Africa region, and equals } 0 \\
\text { otherwise. }\end{array}$ & Authors \\
\hline$S A$ & SA equals 1 for the countries that belong to the South Asia region, and equals 0 otherwise. & Authors \\
\hline SSA & $\begin{array}{l}\text { SSA equals } 1 \text { for the countries that belong to the Sub-Saharan Africa region, and equals } 0 \\
\text { otherwise. }\end{array}$ & Authors \\
\hline
\end{tabular}


Table 2 Low- and middle-income countries in the sample by region

\begin{tabular}{|c|c|c|c|c|c|}
\hline $\begin{array}{l}\text { Sub-Saharan Africa } \\
\text { (SSA) }\end{array}$ & Latin America \& Caribbean (LAC) & $\begin{array}{l}\text { Europe \& Central Asia } \\
\text { (ECA) }\end{array}$ & $\begin{array}{l}\text { East Asia \& Pacific } \\
\text { (EAP) }\end{array}$ & $\begin{array}{l}\text { Middle East \& North Africa } \\
\text { (MENA) }\end{array}$ & $\begin{array}{l}\text { South Asia } \\
\text { (SA) }\end{array}$ \\
\hline Botswana & Argentina & Albania & Cambodia & Algeria & Bangladesh \\
\hline Burkina Faso & Belize & Armenia & China & Djibouti & India \\
\hline Cabo Verde & Brazil & Azerbaijan & Indonesia & Jordan & Maldives \\
\hline Cameroon & Colombia & Belarus & Lao PDR & Morocco & \\
\hline Chad & Costa Rica & Bulgaria & Malaysia & Tunisia & \\
\hline Congo, Rep. & Dominican Rep. & Croatia & Philippines & & \\
\hline Cote d'Ivoire & Ecuador & Georgia & Thailand & & \\
\hline Ethiopia & El Salvador & Kazakhstan & Vietnam & & \\
\hline Gambia, The & Guatemala & Moldova & & & \\
\hline Guinea-Bissau & Guyana & Romania & & & \\
\hline Lesotho & Haiti & Russian Fed. & & & \\
\hline Madagascar & Honduras & Serbia & & & \\
\hline Malawi & Jamaica & Ukraine & & & \\
\hline Mali & Mexico & & & & \\
\hline Namibia & Nicaragua & & & & \\
\hline Niger & Panama & & & & \\
\hline Sao Tome and Principe & Paraguay & & & & \\
\hline Sierra Leone & Peru & & & & \\
\hline South Africa & Suriname & & & & \\
\hline Sudan & Venezuela, RB & & & & \\
\hline \multicolumn{6}{|l|}{ Swaziland } \\
\hline \multicolumn{6}{|l|}{ Tanzania } \\
\hline \multicolumn{6}{|l|}{ Togo } \\
\hline Zambia & & & & & \\
\hline
\end{tabular}

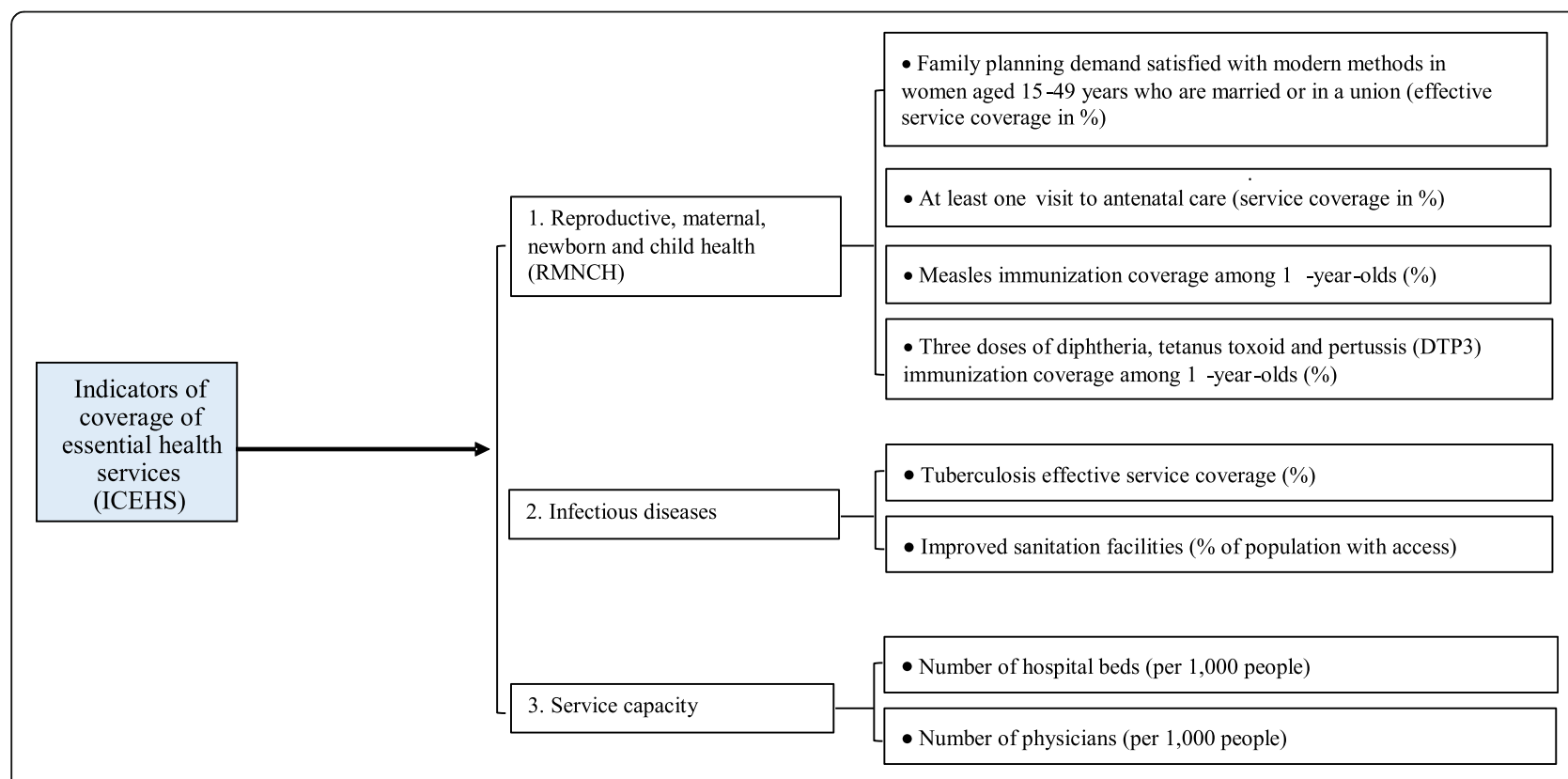

Fig. 2 Selected essential health services indicators 
representing overall coverage of essential health services (indicators of coverage of essential health services, ICEHS):

$$
\operatorname{ICEHS}_{\mathrm{ji}}=\alpha \operatorname{lagIFFT}{ }_{\mathrm{i}}+\beta \ln \mathrm{GDPpc}_{\mathrm{i}}+\varepsilon_{\mathrm{i}}
$$

where $\mathrm{i}=1, \ldots, \mathrm{N}$ are the 72 countries in the available sample. ICEHS $S_{\mathrm{ji}}$ represents the imputed values for the period 2008-2013 of the specific indicator (j) for country (i) (see Table 3) and $\varepsilon_{i}$ represents the error term. The variable (lagIFFT) represents mean values of the variable IFFT for the period 2002-2007 as it was assumed that it takes time before a change in the relative magnitude of IFFs from a country may have an effect on the provision of essential health services. For this reason, this variable was lagged by one period, such that the IFFT in period 2002-2007 had an effect on health service indicators in 2008-2013. Eq. (1) also includes as an independent variable the average level of GDP per capita in natural logs (ln GDPpc) for the period 2008-2013, which in general is a proxy for overall affluence in a country. This factor may affect ICEHS in ways not mediated by other determinants of the provision of essential services.

Finally, for the sake of simplicity and comparability between different models, an augmented model was estimated using the additional controls. $\left(\mathrm{X}_{\mathrm{i}}\right)$ represents a set of $(\mathrm{k})$ variables (also mean values for the period 20082013) which themselves may not be considered a direct outcome of the level of IFFTs.

$$
\mathrm{ICEHS}_{\mathrm{ji}}=\alpha \operatorname{lagIFFT} \mathrm{i}_{\mathrm{i}}+\beta \ln \mathrm{GDPpc}_{\mathrm{i}}+\gamma_{\mathrm{k}} \mathrm{X}_{\mathrm{ki}}
$$

These control variables are as follows (see Table 3 and Table A2 in additional file 1):

- Gross intake ratio in 1st grade of primary education, female, which was used as a proxy for the educational level of mothers in the country. The use of this proxy was based on the assumption that educated mothers are more likely to adopt preventive behaviours and to use maternal and infant health services.

- Urban population, as a percentage of the total population. This variable was chosen on the basis that rural populations lag behind their urban counterparts in access to most of the essential health services [56].

It important to note that the literature shows that there are additional factors not included in eq. (2) that have an impact on the coverage of essential health services (e.g. public and private health expenditures, donor assistance to health, or the quality of governance). However, given that these variables could themselves be considered outcomes of the variable of interest (IFFT) (see
[31] -[36]), these additional controls were not included in eq. (2) with the aim of avoiding a potential 'bad control' problem [57].

In eqs. (1) and (2), the parameter of interest is $(\alpha)$. This coefficient quantifies the strength of association between lagIFFT and the different indicators included in variable ICEHS, all other control variables being equal. For the reasons previously discussed, it was expected that the estimated coefficient $(\alpha)$ would be negative and significant in both models. This result would show that a higher level of IFFT in the period 2002 to 2007 would be associated with a reduction in ICEHS coverage over the next period 2008 to 2013.

The classic linear regression model includes a wide range of circumstances in which the explanatory variables are endogenous (i.e. are correlated with the disturbance), such that OLS regression does not yield consistent estimates. In fact, a regression model can have more than one source of endogeneity. The empirical model proposed in this article includes at least three relevant examples of these circumstances: measurement errors in variables, relevant omitted variables, and simultaneity bias due to reverse causality. As a way to illustrate the endogeneity problem in the estimation of baseline model, it should be recalled that we are assuming that this model allows us to quantify what effect (if any) a change in the "independent" lagIFFT might have on the "dependent" variable (e.g. DTP3), all else being equal. On the one hand, the observed existence of a negative relationship between IFFT and DTP3 levels could be the consequence of the existence of an unobserved effect generated by an omitted variable, such as the country's corruption level. This would have an effect on both variables (i.e. an increase in corruption may decrease DTP3 coverage levels and, at the same time, increase the level of IFFT). Thus, both DTP3 and IFFT move in opposite directions because both variables are impacted by a change in the level of corruption rather than by the existence of a direct causal relationship between both variables. On the other hand, it is relevant to take into account that eq. (1) defines a causal ordering between the variables: the value of DTP3 follows from those of IFFT and this implies that IFFT should not be affected by changes in DTP3 (i.e. IFFT should be exogenous). Otherwise, the existence of inverse causality (or simultaneity) would lead to the OLS estimator giving biased and inconsistent estimates of parameters (i.e. simultaneity bias). One way to avoid these problems would be to employ instrumental variable (IV) methods, which generate consistent estimates provided that it is possible to find instruments that are (at least asymptotically) correlated with the endogenous independent variable and uncorrelated with the error term.

Sometimes theory can suggest which explanatory or independent variables in a model may be potentially 
Table 3 Descriptive analysis of the variables used in the estimations

\begin{tabular}{|c|c|c|c|c|c|}
\hline Variables & Obs. & Mean & SD. & Min. & Max. \\
\hline \multicolumn{6}{|l|}{ Dependent } \\
\hline Family planning, coverage (\%) & 73 & 59.94 & 20.51 & 14.63 & 95.32 \\
\hline Antenatal care, coverage (\%) & 65 & 90.45 & 11.93 & 42.50 & 100.00 \\
\hline DTP3, coverage (\%) & 73 & 88.13 & 10.86 & 34.67 & 99.00 \\
\hline Measles, coverage (\%) & 73 & 87.67 & 11.27 & 47.67 & 99.00 \\
\hline Tuberculosis, coverage (\%) & 73 & 52.88 & 15.12 & 25.15 & 79.58 \\
\hline Sanitation, coverage (\%) & 73 & 62.67 & 28.51 & 9.63 & 98.48 \\
\hline Hospitals beds (per 1000 people) & 64 & 2.43 & 2.20 & 0.20 & 11.20 \\
\hline Physicians (per 1000 people) & 66 & 1.18 & 1.21 & 0.02 & 4.50 \\
\hline \multicolumn{6}{|l|}{ Independent } \\
\hline Lag (IFFT) (\%) & 72 & 12.87 & 10.72 & 1.07 & 49.09 \\
\hline GDPpc (constant 2011 international \$ per capita) & 73 & 8193.31 & 5872.03 & 830.51 & $23,888.91$ \\
\hline GIR, 1st grade of primary education, female (\%) & 68 & 106.7 & 19.70 & 63.37 & 178.33 \\
\hline Urban population (\% of total) & 73 & 52.32 & 18.62 & 15.62 & 91.04 \\
\hline $\operatorname{Lag}(I F F T) \cdot E A P$ & 72 & 0.82 & 2.51 & 0 & 10.43 \\
\hline $\operatorname{Lag}(I F F T) \cdot E C A$ & 72 & 2.47 & 6.63 & 0 & 37.47 \\
\hline $\operatorname{Lag}(I F F T) \cdot L A C$ & 72 & 3.88 & 8.64 & 0 & 36.27 \\
\hline $\operatorname{Lag}(I F F T) \cdot M E N A$ & 72 & 0.73 & 4.60 & 0 & 38.47 \\
\hline $\operatorname{Lag}(I F F T) \cdot S A$ & 72 & 0.29 & 1.59 & 0 & 11.87 \\
\hline $\operatorname{Lag}(I F F T) \cdot S S A$ & 72 & 4.68 & 9.44 & 0 & 49.09 \\
\hline \multicolumn{6}{|l|}{ Excluded instruments } \\
\hline Births attended (\% of total) & 72 & 80.06 & 23.04 & 16.55 & 99.9 \\
\hline$C P I$ & 73 & 3.26 & 0.83 & 1.79 & 6.03 \\
\hline Density (people per km²) & 73 & 117.56 & 203.42 & 2.70 & 1246.67 \\
\hline Dependency (\% of total population) & 73 & 37.97 & 6.79 & 26.40 & 52.50 \\
\hline IFF/GDP (\%) & 73 & 4.84 & 5.47 & 0.33 & 34.00 \\
\hline Labour force participation rate, female (\%) & 73 & 54.08 & 15.50 & 14.67 & 88.27 \\
\hline Lag (Births attended)(\%) & 73 & 73.74 & 27.27 & 6.05 & 99.9 \\
\hline $\operatorname{Lag}(C P I)$ & 73 & 3.03 & 0.86 & 1.62 & 5.83 \\
\hline Lag (GDPpc) (constant 2011 international \$ per capita) & 73 & 6666.92 & 4788.92 & 718.43 & $19,126.04$ \\
\hline $\operatorname{Lag}(I F F / G D P)(\%)$ & 73 & 3.62 & 3.47 & 0.23 & 15.49 \\
\hline Lag (IFF/Population) (international \$ per capita) & 73 & 234.90 & 266.99 & 4.15 & 1150.28 \\
\hline Lag (IFF/Population) $\cdot$ EAP & 73 & 22.65 & 135.85 & 0 & 1150.28 \\
\hline Lag (IFF/Population) $\cdot$ ECA & 73 & 66.65 & 180.48 & 0 & 808.17 \\
\hline Lag (IFF/Population) $\cdot$ LAC & 73 & 91.16 & 217.67 & 0 & 1101.87 \\
\hline Lag (IFF/Population) $\cdot$ MENA & 73 & 9.56 & 45.71 & 0 & 344.27 \\
\hline Lag (IFF/Population) $\cdot$ SA & 73 & 4.02 & 30.08 & 0 & 256.19 \\
\hline Lag (IFF/Population) $\cdot$ SSA & 73 & 40.86 & 102.81 & 0 & 469.57 \\
\hline Lag (Labour force participation rate, female)(\%) & 73 & 53.09 & 15.48 & 12.67 & 88.23 \\
\hline Lag (Urban population)(\%) & 73 & 49.66 & 18.84 & 15.01 & 89.99 \\
\hline Literacy & 60 & 81.53 & 19.98 & 15.46 & 99.97 \\
\hline Ln Population (inhabitants) & 73 & 16.24 & 1.77 & 12.08 & 21.02 \\
\hline
\end{tabular}


endogenous, especially in the case of simultaneity or omitted variables, but it cannot indicate whether the correlation of regressors with the error term is sufficiently large as to invalidate the OLS estimation due to its inconsistency. One solution to this problem is to study the possible endogeneity of the regressors from an empirical perspective and perform tests to determine whether the independent variables being tested have to be treated as endogenous. In applied research, an independent variable is said to be endogenous if it is correlated with the error term [58]. This forms the basis to study the possible endogeneity of the regressors from an empirical perspective independently of the exact source of endogeneity. For this reason, we employed endogeneity tests to study whether independent variables can be treated as exogenous ones.

However, prior to this approach, instruments have to be identified that are strongly correlated with the potentially endogenous variables but are uncorrelated with the error term. Regarding this point, it is crucial to ensure the relevance of the instruments, because if the instruments used are weak, endogeneity tests can lead to misleading results. In other words, instrumentation is made possible by a set of instrumental variables that fulfil the following conditions: they are uncorrelated with the disturbance term (are exogenous); they are correlated with the endogenous regressor (are relevant); and they are not included in the original equation (the instruments have no causal impact on the dependent variable except through their effects on the endogenous variable). Thus, a relevant and exogenous instrument may capture the part of the variations of the endogenous variable which are exogenous. These exogenous variations can also be used to estimate the truth effect of the endogenous variable on the dependent variable by means of IV estimators (such as the Two-Step Least Squares [2SLS] estimator).

In this study, the endogenous regressors and the excluded instruments considered in each regression are identified in the footnotes to the tables showing the estimations results. In order to test whether a regressor can be treated as exogenous, we used the endogtest ( ) option of the ivreg2 program developed in Stata [59]. This option reports a test statistic that is robust to various violations of conditional homoscedasticity. If the results of these tests applied to the explanatory variables in the model show that the hypothesis of exogeneity cannot be rejected, then, in principle, these variables can themselves be valid (included) instruments for the estimation. In those cases where the exogeneity hypothesis can be rejected, excluded instruments were used for the endogenous regressors in the model. Thus, in order to test whether the excluded instruments were relevant, we used an underidentification test (heteroscedasticity-robust Kleinbergen-Paap rk LM statistic) and a weak identification test (the robust Kleinbergen-Paap rk Wald F statistic). We also used a test for redundancy of instruments and the robust Hansen's J statistic to select a set of excluded instruments which are uncorrelated with the error term and are correctly excluded from the estimated equation. An additional file shows this procedure in more detail (see Additional file 2).

\section{Results}

Box-and-Whisker plots are shown in Figs. 3, 4, and 5, which depict the distribution of values across countries by individual tracer indicators. In the case of reproductive, maternal, newborn, and child health (RMNCH) indicators, Fig. 3 shows that the family planning coverage has the greatest dispersion, ranging from 15\% (Chad) to 95\% (China). Antenatal care coverage has the lowest interquartile range after excluding outliers such as Ethiopia, Chad, and Lao PDR. Child immunisation indicators (measles and DPT3 coverage) have very similar distributions, with a median value of around $88 \%$. However, after excluding outliers, the distribution of measles immunisation coverage has a higher degree of asymmetry.

Figure 4 shows the plots of the two individual indicators for infectious diseases. There was also substantial variation in household access to at least basic sanitation coverage, ranging from $9.6 \%$ in the case of Niger to $98.5 \%$ in the case of Jordan. Regarding this public health key intervention, it can be seen that the interquartile range is even greater than that of family planning coverage. However, there were no outliers for tuberculosis and basic sanitation indicators. Finally, Fig. 5 shows the distribution of values of the service capacity indicators. Current values across countries for the indicator hospitals beds per 1000 people ranged from 0.2 (Madagascar) to 11.2 (Belarus), with a median value of less than 2 beds per 1000 people. However, Belarus, among other countries, is a clear outlier in this distribution. Excluding these outliers, the box shows that the maximum value of the distribution is 4.5 beds per 1000 people (corresponding to Argentina). The values for physicians per 1000 people ranged 0.02 (Malawi) to 4.5 (Georgia), and also have a very asymmetric distribution.

As mentioned, the 2SLS estimator was used to control for endogeneity and to eliminate biases and inconsistencies in the estimations for each ICEHS indicator. Table 4 shows the estimation results (heteroscedasticity-consistent) for eq. (1). In most cases, all the estimated coefficients presented the expected signs in the regressions. A negative association was found between the relative level of lagIFFT and all RMNCH indicators (Table 4, columns 1-4). No significant association was found in the case of infectious diseases indicators (effective tuberculosis 


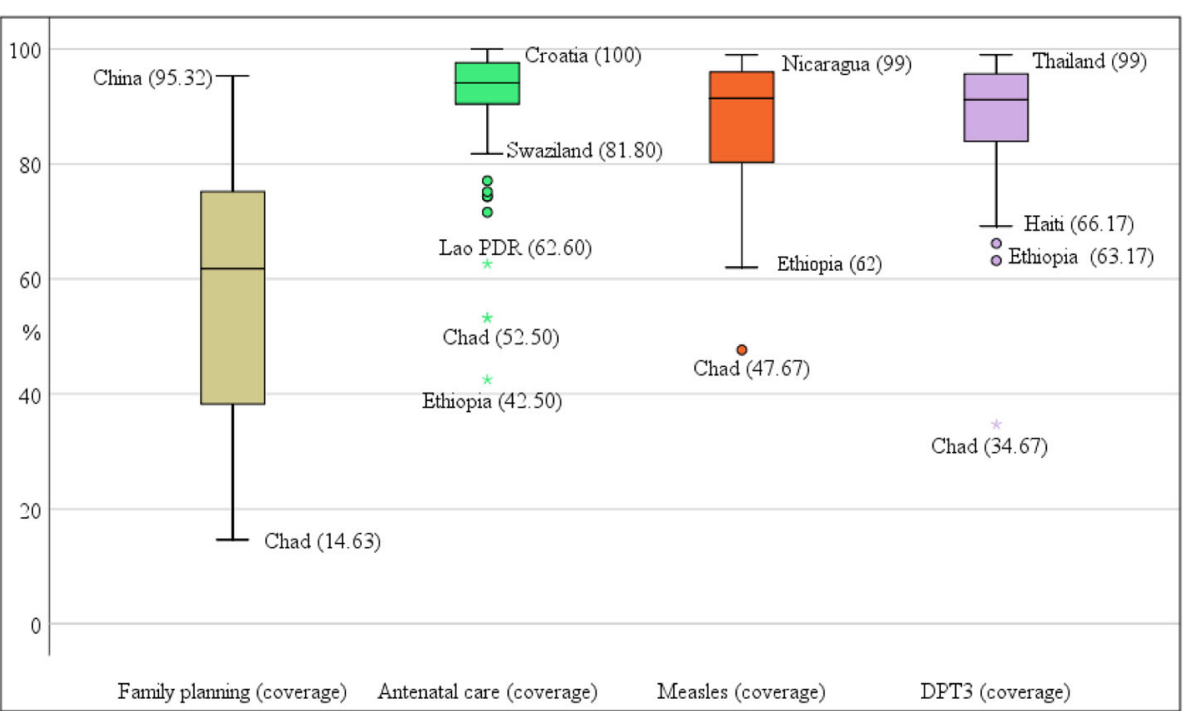

Fig. 3 Box-and-Whisker plots of individual RMNCH tracer indicators for the countries in the sample and the period 2008 to 2013 . The box in the plot represents the interquartile range. The top of the box demarcates the third quartile and the bottom denotes the first. The horizontal line in the middle of the box represents the median of the distribution. The circles and asterisks represent outliers. The horizontal lines (whiskers) indicate the maximum and minimum values of the distribution excluding outliers. Average values for the period are shown in parentheses

treatment coverage and the coverage of households with access to basic sanitation), and the service capacity indicators considered (Table 4, columns 5-8).

Estimating eq. (2) (i.e. the baseline model with additional controls), the 2SLS results confirm that there was a negative association between IFFT and all $\mathrm{RMNCH}$ indicators, and that there were no significant associations between IFFT and infectious diseases and IFFT and service capacity indicators. The robustness of the results obtained using the 2SLS estimator is granted if we consider that no problems related to under-identification, weak instruments, or correlation between employed instruments and the disturbance terms were found in any of the estimations (Table 5).

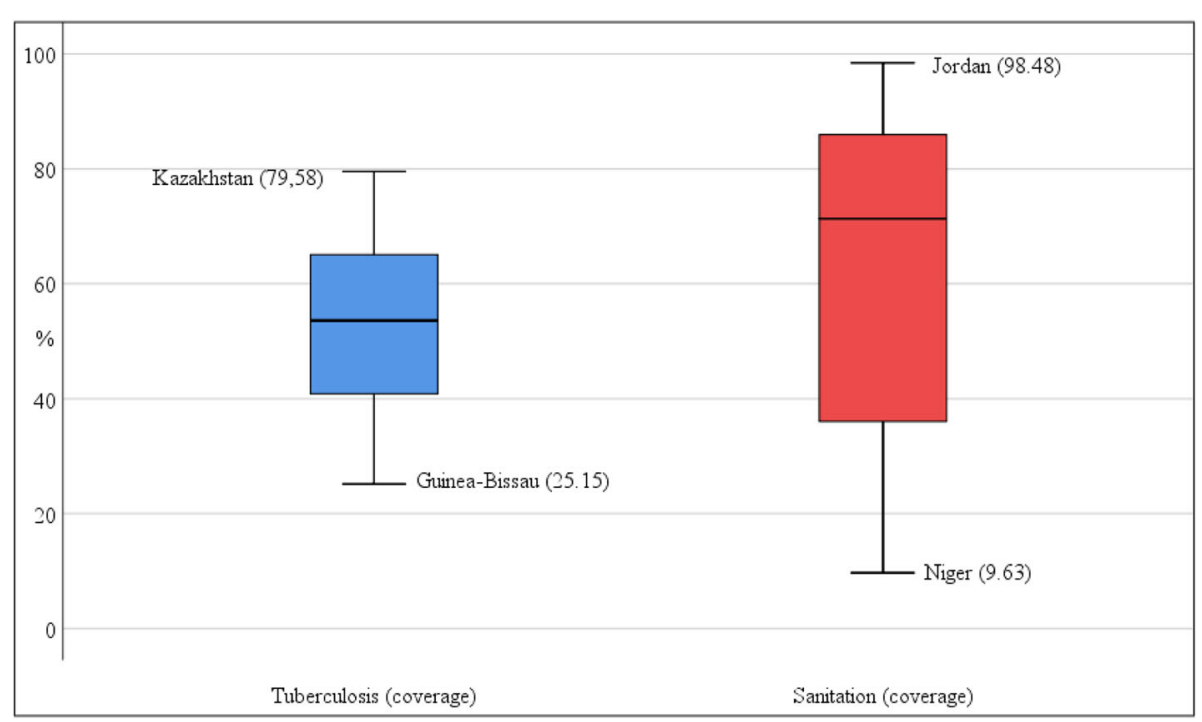

Fig. 4 Box-and-Whisker plots of individual infectious diseases tracer indicators for the countries in the sample and the period 2008 to 2013. The box in the plot represents the interquartile range. The top of the box demarcates the third quartile and the bottom denotes the first. The horizontal line in the middle of the box represents the median of the distribution. The circles and asterisks represent outliers. The horizontal lines (whiskers) indicate the maximum and minimum values of the distribution excluding outliers. Average values for the period are shown in parentheses 


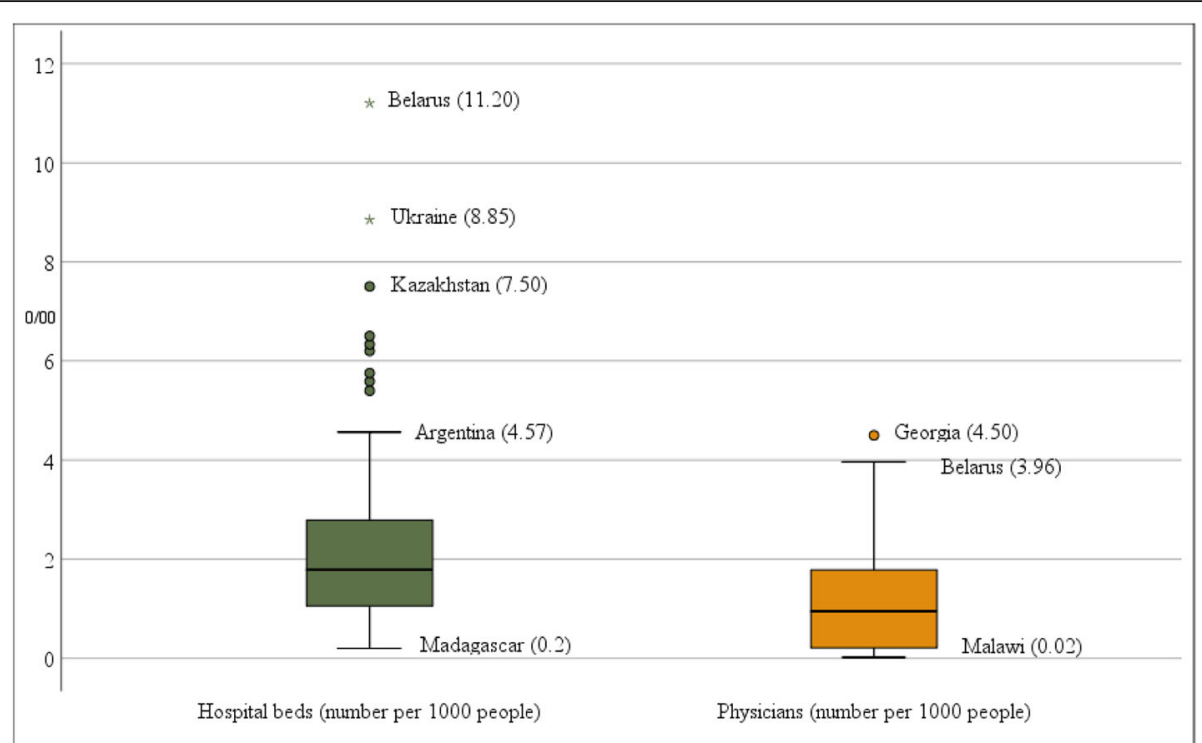

Fig. 5 Box-and-Whisker plots of individual service capacity tracer indicators for the countries in the sample and the period 2008 to 2013. The box in the plot represents the interquartile range. The top of the box demarcates the third quartile and the bottom denotes the first. The horizontal line in the middle of the box represents the median of the distribution. The circles and asterisks represent outliers. The horizontal lines (whiskers) indicate the maximum and minimum values of the distribution excluding outliers. Average values for the period are shown in parentheses

Table 4 2SLS estimations. Baseline model, eq. (1)

\begin{tabular}{|c|c|c|c|c|c|c|c|c|}
\hline \multirow[t]{2}{*}{ Independent variables } & \multicolumn{8}{|c|}{ Dependent variable } \\
\hline & $\begin{array}{l}\text { Family } \\
\text { planning } \\
\text { (1) }\end{array}$ & $\begin{array}{l}\text { Antenatal } \\
\text { care } \\
\text { (2) }\end{array}$ & $\begin{array}{l}\text { DTP3 } \\
\text { (3) }\end{array}$ & $\begin{array}{l}\text { Measles } \\
(4)\end{array}$ & $\begin{array}{l}\text { Tuberculosis } \\
\text { (5) }\end{array}$ & $\begin{array}{l}\text { Sanitation } \\
\text { (6) }\end{array}$ & $\begin{array}{l}\text { In Beds } \\
(7)\end{array}$ & $\begin{array}{l}\text { In Physic } \\
\text { (8) }\end{array}$ \\
\hline$\overline{\operatorname{Lag}(\text { IFFT) }}$ & $-0.299(0.157)$ & $\begin{array}{l}-0.340^{\mathrm{a}} \\
(0.089)\end{array}$ & $\begin{array}{l}-0.611^{c} \\
(0.007)\end{array}$ & $\begin{array}{l}-0.426^{\mathrm{b}} \\
(0.021)\end{array}$ & $0.106(0.350)$ & $\begin{array}{l}-0.254 \\
(0.389)\end{array}$ & $\begin{array}{l}-0.001 \\
(0.934)\end{array}$ & $\begin{array}{l}-0.020 \\
(0.278)\end{array}$ \\
\hline In GDPpC & $7.40^{\complement}(0.000)$ & $\begin{array}{l}10.96^{\mathrm{C}} \\
(0.000)\end{array}$ & $10.95^{\complement}(0.000)$ & $10.66^{c}(0.000)$ & $6.05^{\complement}(0.000)$ & $7.81^{\mathrm{c}}(0.000)$ & $0.07^{\complement}(0.000)$ & $\begin{array}{l}-0.04 \\
(0.287)\end{array}$ \\
\hline RESET test ( $p$-value) & $4.76(0.033)$ & $1.54(0.219)$ & $3.87(0.053)$ & $4.16(0.045)$ & $2.00(0.163)$ & $56.62(0.000)$ & $14.03(0.000)$ & $7.20(0.009)$ \\
\hline K-P rk LM (p-value) & $46.70(0.000)$ & $11.08(0.004)$ & $12.30(0.002)$ & $12.30(0.002)$ & $36.65(0.000)$ & $14.18(0.001)$ & $11.90(0.003)$ & $12.08(0.002)$ \\
\hline $\begin{array}{l}\text { K-P rk F (S-Y 10\% max. IV } \\
\text { size) }\end{array}$ & $\begin{array}{l}88,671.96 \\
(19.93)\end{array}$ & $9.68(13.43)$ & $16.48(19.93)$ & $16.48(19.93)$ & $\begin{array}{l}79,885.44 \\
(19.93)\end{array}$ & $81.77(19.93)$ & $48.94(13.43)$ & $87.86(19.93)$ \\
\hline J statistic (p-value) & $1.11(0.291)$ & $0.09(0.764)$ & $0.03(0.850)$ & $0.04(0.835)$ & $0.32(0.569)$ & $0.26(0.608)$ & $0.17(0.685)$ & $0.05(0.817)$ \\
\hline \# Countries & 72 & 64 & 72 & 72 & 59 & 72 & 63 & 66 \\
\hline
\end{tabular}

Estimated coefficients and statistics, $p$-values in brackets. ${ }^{a}$ Denotes coefficient statistically significant at the $10 \%$ level, ${ }^{\mathrm{b}}$ at the $5 \%$ level, and ${ }^{\mathrm{c}}$ at the $1 \%$ level. Standard errors and covariance are heteroscedasticity-consistent. RESET is the regression equation specification error (heteroscedastic-robust) test designed to test for missing (excluded) regressors. It also has great power to detect non-linearities in the model. Thus, rejection of the null hypothesis could be due to either a nonlinearity or an omitted explanatory variable. The model is identified if the heteroscedasticity-robust Kleinbergen-Paap rk LM statistic for underidentification test $(K-P r k L M)$ rejects the null hypothesis. If the robust Kleinbergen-Paap rk Wald F statistic for weak identification test (K-P rk F) is greater than the Stock and Yogo [60] critical value (S-Y 10\% max. IV relative size), then the null hypothesis of weak instruments can be rejected. The null hypothesis of the robust Hansen's $J$ statistic is that the instruments are uncorrelated with the error term and that excluded instruments are correctly excluded from the estimated equation. The excluded instruments used in the estimations for the instrumented variables are as follows (lagged values of variables (lag) refer to averages of variables for the period 2002-2007):

- Column (1). Instrumented: In GDPpc. Excluded instruments: lag (Urban), lag (In GDPpc)

- Column (2): Instrumented: lag (IFFT), In GDPpc. Excluded instruments: lag (CPI), lag (IFF/Population), lag (In GDPpc)

- Column (3): Instrumented: lag (IFFT). Excluded instruments: lag (CPI), lag (IFF/Population)

- Column (4): Instrumented: lag (IFFT). Excluded instruments: lag (CPI), lag (IFF/Population)

- Column (5): Instrumented: In GDPpc. Excluded instruments: Literacy, lag (In GDPpc)

- Column (6): Instrumented: lag (IFFT). Excluded instruments: lag (CPI), lag (IFF/GDP)

- Column (7): Instrumented: lag (IFFT), In GDPpc. Excluded instruments: lag (CPI), lag (IFF/GDP), lag (In GDPpc).

- Column (8): Instrumented: lag (IFFT). Excluded instruments: lag (CPI), lag (IFF/GDP) 
Table 5 2SLS estimations. Baseline model with additional controls, eq. (2)

\begin{tabular}{|c|c|c|c|c|c|c|c|c|}
\hline \multirow[t]{2}{*}{ Independent variables } & \multicolumn{8}{|c|}{ Dependent variable } \\
\hline & $\begin{array}{l}\text { Family } \\
\text { planning } \\
\text { (1) }\end{array}$ & $\begin{array}{l}\text { Antenatal } \\
\text { care } \\
(2)\end{array}$ & $\begin{array}{l}\text { DTP3 } \\
\text { (3) }\end{array}$ & $\begin{array}{l}\text { Measles } \\
\text { (4) }\end{array}$ & $\begin{array}{l}\text { Tuberculosis } \\
\text { (5) }\end{array}$ & $\begin{array}{l}\text { Sanitation } \\
\text { (6) }\end{array}$ & $\begin{array}{l}\text { In Beds } \\
\text { (7) }\end{array}$ & $\begin{array}{l}\text { In Physic } \\
\text { (8) }\end{array}$ \\
\hline$\overline{\operatorname{Lag}(\text { IFFT) }}$ & $\begin{array}{l}-0.460^{\mathrm{b}} \\
(0.040)\end{array}$ & $\begin{array}{l}-0.312^{\mathrm{b}} \\
(0.031)\end{array}$ & $\begin{array}{l}-0.307^{b} \\
(0.017)\end{array}$ & $\begin{array}{l}-0.334^{b} \\
(0.011)\end{array}$ & $0.113(0.630)$ & $0.193(0.562)$ & $0.002(0.781)$ & $0.007(0.780)$ \\
\hline In GDPpC & $-0.80(0.775)$ & $8.54^{\mathrm{C}}(0.000)$ & $8.50^{C}(0.000)$ & $10.77^{\mathrm{C}}(0.000)$ & $5.25^{c}(0.000)$ & $18.85^{C}(0.000)$ & $0.18^{b}(0.025)$ & $0.52^{\mathrm{b}}(0.034)$ \\
\hline GIR female & $0.314^{b}(0.011)$ & $\begin{array}{l}0.134^{b} \\
(0.044)\end{array}$ & $0.185^{\mathrm{b}}(0.002)$ & $0.051(0.680)$ & $\begin{array}{l}-0.016 \\
(0.817)\end{array}$ & $\begin{array}{l}-0.982^{c} \\
(0.000)\end{array}$ & $\begin{array}{l}-0.012^{b} \\
(0.011)\end{array}$ & $\begin{array}{l}-0.060^{c} \\
(0.002)\end{array}$ \\
\hline Urban & $0.754^{\mathrm{C}}(0.005)$ & $0.122(0.200)$ & $\begin{array}{l}-0.033 \\
(0.750)\end{array}$ & $\begin{array}{l}-0.132 \\
(0.214)\end{array}$ & $0.150(0.160)$ & $0.045(0.872)$ & $0.047(0.499)$ & $0.023(0.129)$ \\
\hline RESET test ( $p$-value) & $0.09(0.770)$ & $0.01(0.942)$ & $3.77(0.057)$ & $0.00(0.984)$ & $0.48(0.492)$ & $3.16(0.081)$ & $0.38(0.542)$ & $0.42(0.518)$ \\
\hline K-P rk LM (p-value) & $14.91(0.001)$ & $15.11(0.000)$ & $16.18(0.001)$ & $26.00(0.000)$ & $14.85(0.000)$ & $12.49(0.002)$ & $23.62(0.000)$ & $12.51(0.000)$ \\
\hline $\begin{array}{l}\text { K-P rk F (S-Y 10\% max. IV } \\
\text { size) }\end{array}$ & $24.09(19.93)$ & $9.74(19.45)$ & $12.05(16.87)$ & $14.79(16.87)$ & $26.27(19.93)$ & $9.49(13.43)$ & $786.81(13.43)$ & $12.99(19.93)$ \\
\hline J statistic ( $p$-value) & $0.29(0.592)$ & $4.72(0.193)$ & $1.26(0.534)$ & $1.15(0.563)$ & $0.12(0.735)$ & $0.00(0.997)$ & $0.02(0.894)$ & $0.18(0.670)$ \\
\hline \# Countries & 67 & 60 & 67 & 67 & 67 & 66 & 60 & 62 \\
\hline
\end{tabular}

Estimated coefficients and statistics, p-values in brackets. ${ }^{a}$ Denotes coefficient statistically significant at the $10 \%$ level, ${ }^{b}$ at the $5 \%$ level, and ${ }^{\mathrm{c}}$ at the $1 \%$ level. Standard errors and covariance are heteroscedasticity-consistent. RESET is the regression equation specification error (heteroscedastic-robust) test designed to test for missing (excluded) regressors. It also has great power to detect non-linearities in the model. Thus, rejection of the null hypothesis could be due to either a nonlinearity or an omitted explanatory variable. The model is identified if the heteroscedasticity-robust Kleinbergen-Paap rk LM statistic for underidentification test $(K-P$ rk LM) rejects the null hypothesis. If the robust Kleinbergen-Paap rk Wald F statistic for weak identification test ( $K-P$ rk $F$ ) is greater than the Stock and Yogo [60] critical value (S-Y 10\% max. IV size), then the null hypothesis of weak instruments can be rejected. The null hypothesis of the robust Hansen's $J$ statistic is that the instruments are uncorrelated with the error term and that excluded instruments are correctly excluded from the estimated equation. The excluded instruments used in the estimations for the instrumented variables are as follows (lagged values of variables (lag) refer to averages of variables for the period 2002-2007):

- Column (1). Instrumented: Urban. Excluded instruments: lag (Births attended), lag (Labour force participation rate, female)

- Column (2): Instrumented: lag (IFFT), In GDPpc. Excluded instruments: lag (IFF/Population), lag (CPI), lag (Births attended), lag (Urban), lag (In GDPpc)

- Column (3): Instrumented: lag (IFFT), Urban. Excluded instruments: lag (IFF/Population), lag (CPI), lag (Labour force participation rate, female), lag (Urban)

- Column (4): Instrumented: lag (IFFT), In GDPpc. Excluded instruments: lag (IFF/Population), lag (CPI), lag (Labour force participation rate, female), lag (Births attended)

- Column (5): Instrumented: lag (IFFT). Excluded instruments: lag (IFF/Population), lag (CPI)

- Column (6): Instrumented: GIR female, In GDPpc. Instruments: lag (Labour force participation rate, female), Births attended, lag (GDPpc)

- Column (7): Instrumented: Urban, In GDPpc. Excluded instruments: lag (Urban), lag (In GDPpc), Labour force participation rate, female

- Column (8): Instrumented: GIR female. Excluded instruments: In Population, Labour force participation rate, female

Thus, taking into account the estimation results obtained from eq. (2), research findings show that, on average, an annual 1 percentage point (p.p.) increase in the ratio of IFFT would be associated with an average 0.460 p.p. decrease in the level of family planning coverage rates and an average 0.312 p.p. decrease in antenatal care coverage rates. Given that there was an estimated annual average of 837 million women aged between 15 and 49 years in the countries included in the full sample, this result suggests that around 3.9 million women would not receive this basic health care intervention as a long run effect of this increase in IFFT. Similarly, an average annual 1 p.p. increase in the ratio of IFFT would be associated with a 0.31 to 0.33 p.p. decrease in the level of infant vaccination coverage rates. It is also noteworthy that in the case of DTP3 and measles, the values of the estimated coefficients for IFFT were not far from the estimated long-run impact of IFFT on the infant vaccination coverage rate $(-0.19$ p.p. in the level of coverage of DPT3, measles, and polio in combination) estimated by Ortega et al. [19], who used panel data regression methods and a sample of 56 LMICS for the period 2002 to 2013. Given that there was an estimated annual average of 65 million infants in the countries in the sample, this result suggests that around 190,000 children may not receive these basic healthcare interventions as a long-run effect of this increase in IFFT.

The margins command in Stata was used to generate predictions of the level of dependent variables for different values of the variable of interest IFFT when the rest of the regressors in the model were evaluated at the sample mean. Next, employing the command marginsplot in Stata, a 95\% confidence interval for the sample average predicted values of the dependent variables at specified values of IFFT (see Figs. 6, 7, 8 and 9). These figures show how a higher level of the variable IFFT is associated with lower estimated coverage in family planning, antenatal care, and infant immunisation coverage.

Robustness checks were also performed to assess the sensitivity of the estimation results obtained from the baseline 


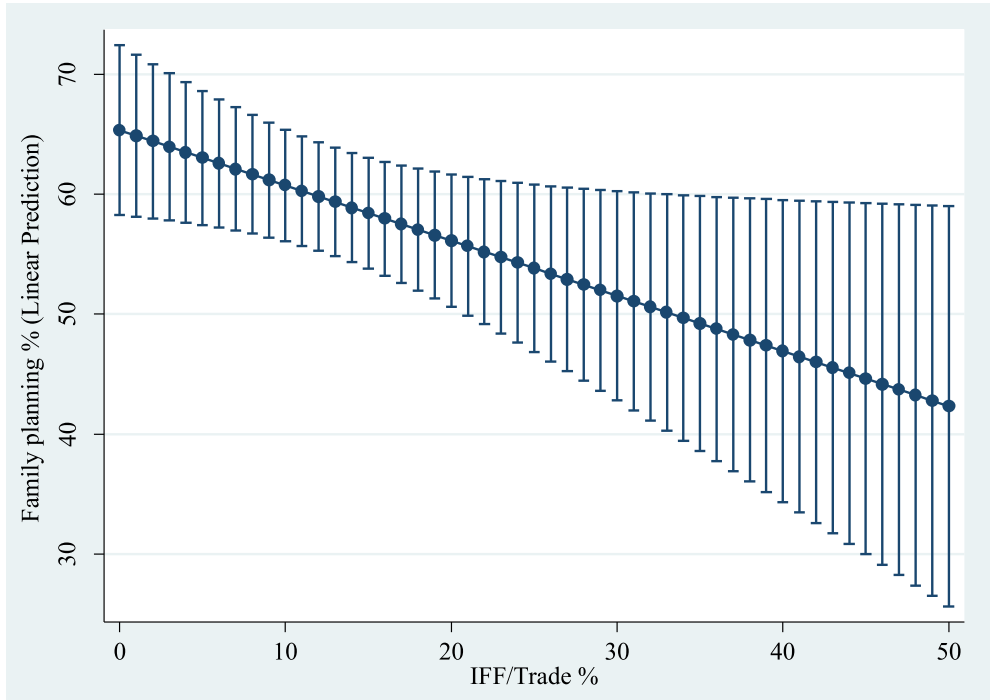

Fig. 6 Influence of IFFT on predicted family planning coverage rates. Predictive margins (with 95\% confidence intervals) while holding every independent variable constant at their sample mean

model to the inclusion of regional effects. With this aim, a set of dummy variables was constructed to control for the region that each country belongs to (SSA, LAC, ECA, EAP MENA, and SA; see Table 2). For example, the variable SSA equals 1 for the countries which belong to the Sub-Saharan Africa region, and equals 0 otherwise. Interaction terms between these regional dummies and the variable of interest (lagIFFT) were included in the base model as regressors. Thus, the estimated model in this case is specified as follows:

$$
\begin{aligned}
& \mathrm{ICEHS}_{\mathrm{ii}}=\alpha_{\mathrm{EAP}} \mathrm{EAP}_{\mathrm{i}} \cdot \operatorname{lagIFFT} \mathrm{i}_{\mathrm{i}}+\alpha_{\mathrm{ECA}} \mathrm{ECA}_{\mathrm{i}} \\
& \cdot \operatorname{lagIFFT}_{\mathrm{i}}+\alpha_{\mathrm{LAC}} \mathrm{LAC}_{\mathrm{i}} \cdot \operatorname{lagIFFT} \mathrm{I}_{\mathrm{i}} \\
& +\alpha_{\text {MENA }} \text { MENA }_{i} \cdot \operatorname{lagIFFT}{ }_{i}+\alpha_{S_{A}} S_{i} \\
& \cdot \operatorname{lagIFFT}{ }_{\mathrm{i}}+\alpha_{\mathrm{SSA}_{\mathrm{S}}} \mathrm{SSA}_{\mathrm{i}} \cdot \operatorname{lagIFFT} \mathrm{T}_{\mathrm{i}} \\
& +\beta \ln \mathrm{GDPpc}_{\mathrm{i}}+\varepsilon_{\mathrm{i}}
\end{aligned}
$$

The estimation results presented in Table 6 show that there are significant regional effects and that the negative effect of the IFFs is not evenly distributed

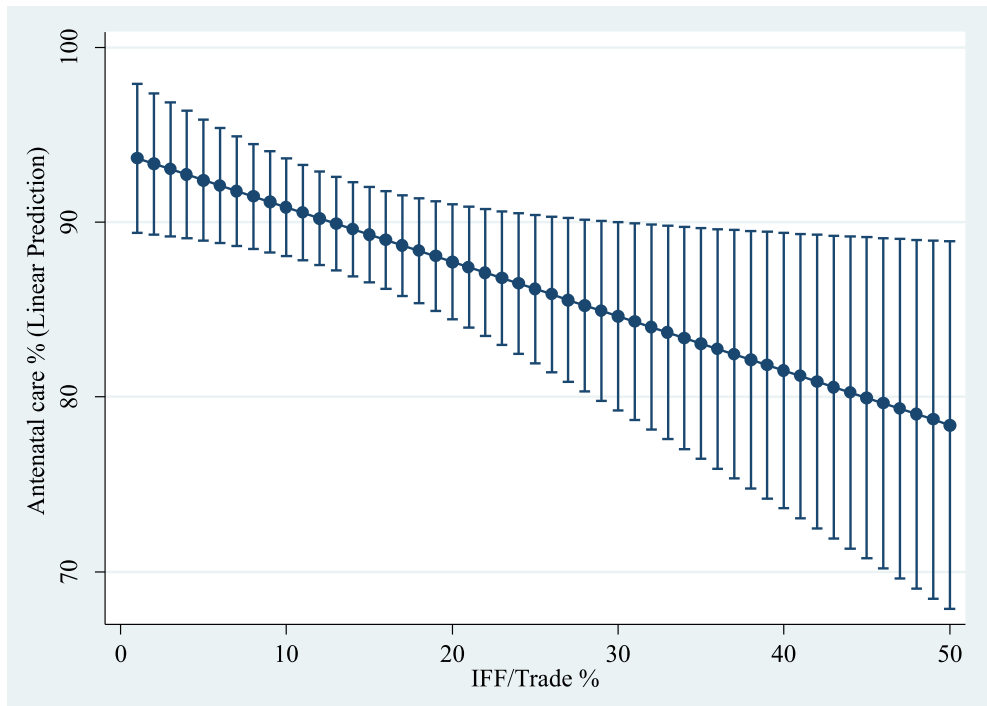

Fig. 7 Influence of IFFT on predicted antenatal care coverage rates. Predictive margins (with 95\% confidence intervals) while holding every independent variable constant at their sample mean 


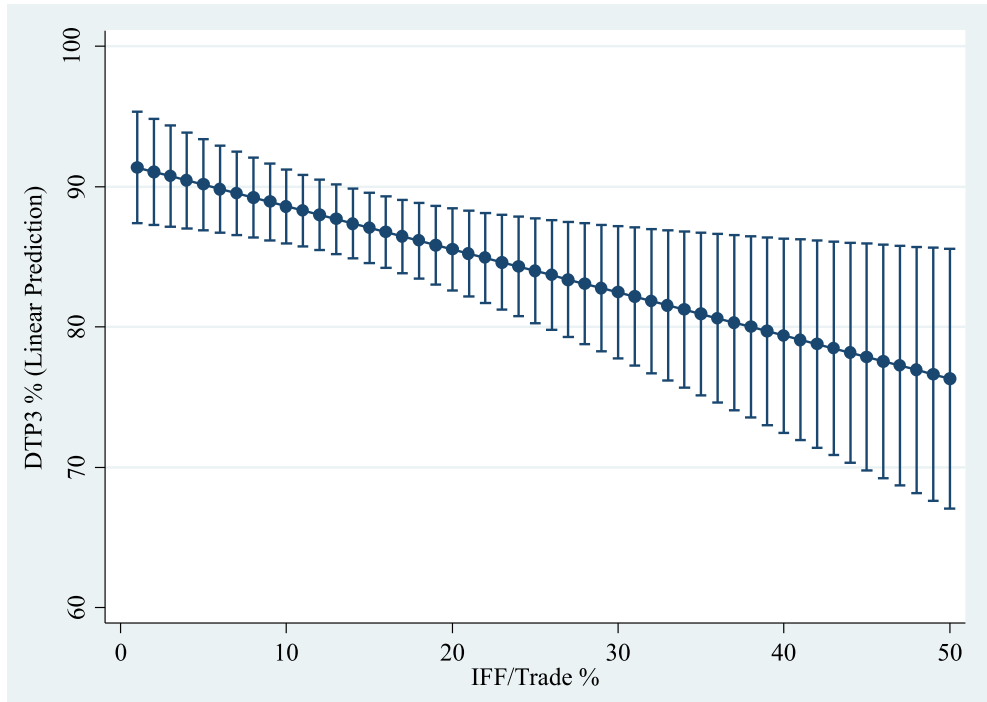

Fig. 8 Influence of IFFT on predicted DTP3 coverage rates. Predictive margins (with 95\% confidence intervals) while holding every independent variable constant at their sample mean

across regions. Specifically, we found that IFFs had a negative association with the variable 'Family Planning' only in countries belonging to ECA, MENA, and SSA regions. In the case of 'Antenatal care', when regional interaction terms are considered, the only region for which a significant negative effect was detected was South Asia (SA). Nevertheless, this result should be taken with caution because this coefficient was estimated with only two degrees of freedom (given that only three countries in the sample belong to this region). The estimation results also suggest that the negative association between IFFs and child immunization was limited to ECA countries. Finally, it is noteworthy that, in relation to effective tuberculosis treatment and sanitation coverage, countries in SSA region were hard hit by IFFs. Given the immense importance of these interventions for health outcomes, attention should be paid to the potential severe negative effect on health that IFFs may have in this region.

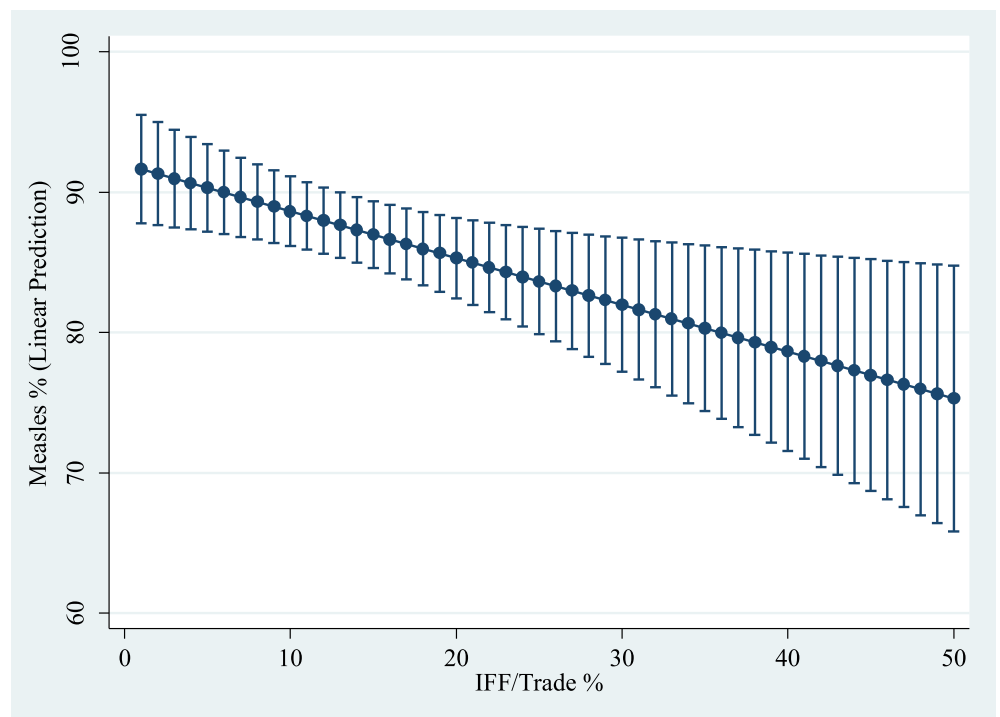

Fig. 9 Influence of IFFT on predicted measles coverage rates. Predictive margins (with 95\% confidence intervals) while holding every independent variable constant at their sample mean 
Table 6 2SLS estimations. Baseline model with regional effects, eq. (3)

\begin{tabular}{|c|c|c|c|c|c|c|c|c|}
\hline \multirow{2}{*}{$\begin{array}{l}\text { Independent } \\
\text { variables }\end{array}$} & \multicolumn{8}{|c|}{ Dependent variable } \\
\hline & $\begin{array}{l}\text { Family } \\
\text { planning } \\
\text { (1) }\end{array}$ & $\begin{array}{l}\text { Antenatal care } \\
\text { (2) }\end{array}$ & $\begin{array}{l}\text { DTP3 } \\
\text { (3) }\end{array}$ & $\begin{array}{l}\text { Measles } \\
\text { (4) }\end{array}$ & $\begin{array}{l}\text { Tuberculosis } \\
\text { (5) }\end{array}$ & $\begin{array}{l}\text { Sanitation } \\
\text { (6) }\end{array}$ & $\begin{array}{l}\text { In Beds } \\
\text { (7) }\end{array}$ & $\begin{array}{l}\text { In Physic } \\
\text { (8) }\end{array}$ \\
\hline EAP.Lag (IFFT) & $0.464(0.691)$ & $-0.684(0.178)$ & $-0.301(0.473)$ & $-0.476(0.327)$ & $-1.146(0.214)$ & $\begin{array}{l}-0.882 \\
(0.310)\end{array}$ & $-0.047(0.134)$ & $-0.052(0.449)$ \\
\hline ECA.Lag (IFFT) & $-1.052^{\complement}(0.008)$ & $-0.181(0.315)$ & $\begin{array}{l}-0.326^{b} \\
(0.037)\end{array}$ & $\begin{array}{l}-0.242^{b} \\
(0.050)\end{array}$ & $0.021(0.949)$ & $0.346(0.179)$ & $0.057^{c}(0.002)$ & $0.086^{\mathrm{C}}(0.007)$ \\
\hline LAC Lag (IFFT) & $0.451(0.148)$ & $-0.166(0.303)$ & $\begin{array}{l}-0.285^{\mathrm{a}} \\
(0.068)\end{array}$ & $-0.219(0.169)$ & $-0.074(0.743)$ & $\begin{array}{l}-0.032 \\
(0.884)\end{array}$ & $-0.022^{\mathrm{a}}(0.052)$ & $0.033(1.16)$ \\
\hline MENA Lag (IFFT) & $-0.606^{\mathrm{C}}(0.001)$ & $0.038(0.670)$ & $0.162^{\mathrm{a}}(0.067)$ & $0.024(0.771)$ & $0.300(0.138)$ & $\begin{array}{l}-0.382^{a} \\
(0.094)\end{array}$ & $-0.010(0.046)$ & $\begin{array}{l}-0.015 \\
(0.517)\end{array}$ \\
\hline SA Lag (IFFT) & $0.842(0.198)$ & $\begin{array}{l}-2.409^{c} \\
(0.000)\end{array}$ & $0.343(0.696)$ & $0.109(0.866)$ & $\begin{array}{l}-1.392^{\mathrm{a}} \\
(0.059)\end{array}$ & $-2.365(0.150)$ & $-0.102^{c}(0.001)$ & $-0.027(0.603)$ \\
\hline SSA.Lag (IFF/Trade) & $-0.646^{\mathrm{C}}(0.009)$ & $0.133(0.595)$ & $0.006(0.981)$ & $-0.211(0.337)$ & $\begin{array}{l}-0.547^{\mathrm{a}} \\
(0.058)\end{array}$ & $\begin{array}{l}-2.641^{c} \\
(0.000)\end{array}$ & $\begin{array}{l}-0.037^{b} \\
(0.031)\end{array}$ & $\begin{array}{l}-0.130^{c} \\
(0.002)\end{array}$ \\
\hline In GDPpC & $7.35^{\complement}(0.000)$ & $10.69^{c}(0.000)$ & $10.33^{c}(0.000)$ & $10.38^{\mathrm{C}}(0.000)$ & $6.50^{c}(0.000)$ & $8.72^{c}(0.000)$ & $0.08^{\complement}(0.000)$ & $0.35(0.360)$ \\
\hline $\begin{array}{l}\text { RESET test ( } p \text { - } \\
\text { value) }\end{array}$ & $0.16(0.688)$ & $1.71(0.196)$ & $3.06(0.085)$ & $3.00(0.088)$ & $0.07(0.792)$ & $12.07(0.001)$ & $0.14(0.701)$ & $9.71(0.003)$ \\
\hline K-P rk LM ( $p$-value) & $21.60(0.001)$ & $20.23(0.003)$ & $21.60(0.001)$ & $21.60(0.001)$ & $23.44(0.005)$ & $23.44(0.005)$ & $23.44(0.005)$ & $23.25(0.313)$ \\
\hline K-P rk F & 5.30 & 5.16 & 5.30 & 5.30 & 7.04 & 7.04 & 3.88 & 4.14 \\
\hline J statistic ( $p$-value) & $6.99(0.222)$ & $7.11(0.212)$ & $5.11(0.403)$ & $5.55(0.353)$ & $10.80(0.214)$ & $9.50(0.302)$ & $12.39(0.192)$ & $14.18(0.165)$ \\
\hline \# Countries & 72 & 64 & 72 & 72 & 71 & 71 & 62 & 65 \\
\hline
\end{tabular}

Estimated coefficients and statistics p-values in brackets. ${ }^{\mathrm{a}}$ Denotes coefficient statistically significant at the $10 \%$ level, ${ }^{\mathrm{b}}$ at the $5 \%$ level, and ${ }^{\mathrm{c}}$ at the $1 \%$ level. Standard errors and covariance are consistent to various violations of conditional homoscedasticity. RESET is the regression equation specification error (heteroscedastic-robust) test designed to test for missing (excluded) regressors. It also has great power to detect non-linearities in the model. Thus, rejection of the null hypothesis could be due to either a nonlinearity or an omitted explanatory variable. If the heteroscedasticity-robust Kleinbergen-Paap rk LM statistic for underidentification test (K-P rk LM) rejects the null hypothesis, then the model is identified. The weak identification test (K-P rk F) is the robust Kleinbergen-Paap rk Wald F statistic. The null hypothesis of the robust Hansen's $J$ statistic is that the instruments are uncorrelated with the error term and that excluded instruments are correctly excluded from the estimated equation. The excluded instruments used in the estimations for the instrumented variables are as follows (lagged values of variables (lag) refer to averages of variables for the period 2002-2007):

- Columns (1), (2), (3) and (4): Instrumented: Interaction terms between the six regional dummies and lag (IFFT), In GDPpc. Excluded instruments: Regional dummies, and interaction terms between the six regional dummies and lag (IFF/Population)

- Columns (5) and (6): Instrumented: Interaction terms between the six regional dummies and lag (IFFT), In GDPpc. Excluded instruments: Regional dummies, and interaction terms between the six regional dummies and lag (IFF/Population), CPI, Births attended, Urban

- Column (7): Instrumented: Interaction terms between the six regional dummies and lag (IFFT), In GDPpc. Excluded instruments: Regional dummies, and interaction terms between the six regional dummies and lag (IFF/Population), Births attended, lag (Urban), lag (In GDPpc), Labour force participation rate, female - Column (8): Instrumented: Interaction terms between the six regional dummies and lag (IFFT), In GDPpc. Excluded instruments: Regional dummies, and interaction terms between the six regional dummies and lag (IFF/Population), Births attended, Dependency, lag (In GDPpc), Density

\section{Discussion}

Illicit financial flows are a global problem that have recently come under increased scrutiny by international policy communities, including the World Bank and the UN systems. The negative effects of increasing IFFs on development calls for the urgent need to reduce these flows, which would reduce the resource gap to finance the provision of public services and investments while simultaneously stabilizing public debt levels [61]. Given this background, this study quantified the strength of association between IFFs and the coverage of essential health-care services in LMICS.

While controlling for a range of relevant factors, the main result of the empirical analysis was that the relative level of IFFs over this period had a negative association with family planning service coverage, antenatal care service coverage, and infant DPT3 and measles vaccination coverage. These research findings also suggest that it is not simply the volume of IFFs that is curbing relevant $\mathrm{RMNCH}$ interventions coverage; rather, what seems to harm these ICEHS are periods in which there is an increase in the ratio of IFFs to total trade. These findings are particularly relevant given that $\mathrm{RMNCH}$ interventions encompass health concerns across the life course, ranging from adolescent girls and women before and during pregnancy and delivery, to newborn babies (i.e. in the first month of life), and to children.

Nevertheless, some limitations of this empirical analysis should be noted. This study uses data at the country level and it must be recognised that the negative effects of IFFs on the provision of ICEHS would likely have a greater impact on low-income rural subpopulations within countries. In this regard, Boerma et al. [62] noted that within-country inequalities in 
coverage have slowly fallen in most countries, and that in several countries significant poor-rich, urban-rural, or geographical gaps persist in most $\mathrm{RMNCH}$ indicators. Unfortunately, no data were available to analyse such a differential effect. Further research is also needed to study the effects of IFFs on the provision of other ICEH $\mathrm{S}$, such as non-communicable diseases (NCD). However, this dimension of healthcare has not been addressed in this study due to lack of data. The estimation results also show that the negative influence of IFFs is not evenly distributed across regions. For this reason, the sample of countries included in the analysis must be enlarged to obtain more general results and implement specific regional analyses. Finally, it is important to note that, in a regression analysis, the estimated dependence of one variable on other variables does not necessarily imply causation: a rigorous statistical causal hypothesis test has to be grounded on an explicit and solid theoretical model. Nevertheless, social science research is frequently based on weak or incomplete theories, and its empirical generalizations are almost always the outcome of numerous iterations [63]. Taking this into account, the negative associations documented in this article could indicate that IFFs have a negative influence on the provision of basic health care interventions. However, although we consider that this effect is mainly due to reductions in the governmental fiscal resources available for investment in sectors with an impact on health outputs and outcomes (i.e. because of resource leakages in the form of IFFs), the exact channels through which this effect may occur deserve further research.

\section{Conclusions}

The research findings suggest that IFFs are associated with damage to the provision of modern family planning methods and antenatal care. Thus, the resources lost through IFFs, and the following lack of stability of funding [64], would be associated with the fact that more than 214 million women in developing countries who want to avoid pregnancy are not using a modern contraception method [65], and that in SSA, 24\% of women have an unmet need for family planning [66]. These effects are of prime importance, not only to the well-being of a population, but also to the long-term development prospects of poor countries $[65,67]$. Early investment in family planning would significantly reduce unwanted pregnancies and birth rates, and yield significant savings in the costs of maternal and newborn care and immunization [68]. Furthermore, infertility is also a covert burden of reproductive health. This issue is of particular concern in LMICs, where having children is highly valued. Thus, infertility can lead to severe social stigma, economic deprivation, denial of inheritance, divorce, and social isolation. In other words, the benefits of family planning pay dividends over many years, and make it easier to achieve other development goals [69].

Furthermore, an increase in the IFFT would be associated with a decrease in the level of measles and DPT3 vaccine coverage. This is a very significant association given that immunisation tops the list of basic health care interventions of proven effectiveness in improving health status [70]. Moreover, despite immense progress during the 1980s, an estimated 19.4 million infants worldwide are still not reached by routine immunisation services. Close to $60 \%$ of these children live in Angola, the Democratic Republic of the Congo, Ethiopia, India, Indonesia, Iraq, Nigeria, Pakistan, the Philippines, and the Ukraine [71]. Thus, the loss of domestic resources through IFFs would explain why low immunisation coverage has been observed in countries experiencing high relative levels of IFFs, such as Ethiopia and the Democratic Republic of the Congo in SSA or Azerbaijan and Georgia in ECA regions, among others.

Future research should assess the specific effects of IFFs on public resources invested in health, and analyse how these flows can be curtailed such that healthrelated SDGs can be achieved, especially in developing countries. Further research should also analyse the observed differential regional effects and attempt to explain these findings. Nevertheless, the research findings suggest that the volume of IFFs in LMICs must be reduced in order to improve the living conditions of their populations. This objective must be addressed at the global level, not only because it is a humanitarian issue, but also because of the effects of IFFs on growth and development in LMICs. This issue becomes even more pressing if the time has come to envisage health services across countries as a global public good.

\section{Supplementary information}

Supplementary information accompanies this paper at https://doi.org/10. 1186/s12914-020-00236-w.

\section{Additional file 1.}

Additional file 2.

\section{Abbreviations}

AAAA: Addis Ababa Action Agenda; CPI: Corruption Perceptions Index; DTP3: Three doses of combined diphtheria, tetanus toxoid and pertussis vaccine; EAP: East Asia \& Pacific; ECA: Europe \& Central Asia; FDI: Foreign direct investment; GDP: Gross Domestic Product; GFI: Global Financial Integrity; GIR: Gross intake ratio in first grade of primary education; GNI: Gross National Income; HE: Health expenditure; ICEHS: Indicators of coverage of essential health services; IFFs: Illicit financial flows; IFFT: IFFs to total trade; IV: Instrumental variables; LAC: Latin America \& Caribbean; LMICs: Low- and middle-income countries; MDG: Millennium Development Goals;

MENA: Middle East \& North Africa; NCD: Non-communicable diseases; ODA: Official development assistance; OECD: Organisation for Economic Cooperation and Development; OLS: Ordinary least squares; RESET: The regression equation specification error test; RMNCH: Reproductive, maternal, newborn, and child health; SA: South Asia; SDGs: Sustainable Development 
Goals; SSA: Sub-Saharan Africa; 2SLS: Two-step least squares; UHC: Universal health coverage; UN: United Nations; WHO: World Health Organization

\section{Acknowledgements}

We wish to thank the reviewers and the Editor for their insightful feedback.

\section{Authors' contributions}

$\mathrm{BO}$ conceived the study and developed the methods. $\mathrm{BO}$ and $\mathrm{AC}$ analysed the data. $\mathrm{BO}$ and JS wrote the manuscript. $\mathrm{BO}$ had final responsibility for the decision to submit the study for its publication. All authors revised and approved the final manuscript.

\section{Funding}

No funding was received in support of this study.

\section{Availability of data and materials}

All data employed are publicly available. The dataset used and analysed by the current study are available from the corresponding author on reasonable request. All documents and databases employed are available at: Global Financial Integrity: https://gfintegrity.org/

Transparency International: https://www.transparency.org/ United Nations: http://data.un.org/ and https://population.un.org/ World Bank: https://data.worldbank.org/indicator/

World Health Organization: https://www.who.int/gho/database/

World Trade Organization: https://timeseries.wto.org/

\section{Ethics approval and consent to participate}

Not applicable.

\section{Consent for publication}

Not applicable.

\section{Competing interests}

The authors declare that they have no competing interests.

Received: 25 March 2019 Accepted: 5 July 2020

\section{Published online: 11 July 2020}

\section{References}

1. Keats EC, Macharia W, Singh NS, et al. Accelerating Kenya's progress to 2030: understanding the determinants of under-five mortality from 1990 to 2015. BMJ Glob Health. 2018;3:e000655.

2. Osotimehin B. Family planning save lives, yet investments falter. Lancet. 2012;380:82-3

3. Hodin SM, Caglia JM, Baye M, Bewa J, Waiswa P, Langer A. From MDGs to SDGs: implications for maternal newborn health in Africa. Afr J Reprod Health. September 2016:20(3):26-8.

4. Say L, Raine R. A. Systematic review of inequalities in the use of maternal health care in developing countries: examining the scale of the problem and the importance of context. Bull World Health Organ. 2007;85:812-9.

5. Center for Strategic and International Studies. Improving the Health of Women, Girls, and Families around the World. Will Greater Integration Get Us There? Considerations for the New Administration and Congress. CSIS Task Force on Women's and Family Health, 2017.

6. Upadhyaya UD, Gipsonb JD, Withersc M, Lewise S, Ciaraldib EJ, Fraserd A, Huchkof MJ, Pratad N. Women's empowerment and fertility: A review of the literatura. Soc Sci Med 2014; 0: 111-120.

7. Chowdhury S, Vergeer P, Schmidt H, Bishai D, Halpern S, Barroy H, Cortez R, Seshadri SR, Bansal S. Economics and ethics of results-based financing for family planning: evidence and policy implications. Health, Nutrition, and Population Family (HNP) Discussion Paper 84663. World Bank; 2013.

8. Lissner CL, Ali M. Systematic reviews of mechanisms for financing family planning: findings, implications, and future agenda. Studies in FamilyPlanning. 2016;47(4):295-308

9. Stenberg K, Axelson H, Sheehan P, Anderson I, Gülmezoglu AM, Temmerman M, Mason E, et al. Advancing social and economic development by investing in women's and children's health: a new global investment framework. Lancet. 2014;383:1333-54.

10. United Nations. What would it take to accelerate fertility decline in the least developed countries? New York: United Nations Population Division; 2009.
11. Palmer N, Mueller DH, Gilson L, Mills A, Haines A. Health financing to promote access in low income settings-how much do we know? Lancet. 2004;364:1365-70

12. Meheus F, McIntyre D. Fiscal space for domestic funding of health and other social services. Health Economics Policy Law. 2017;12:159-77.

13. Kar D, Spanjers J. Illicit financial Flows from developing countries: 2004 2013. Global Financial Integrity; 2015.

14. Zucman G. The Missing Wealth of Nations, Are Europe and the U.S. Net Debtors or Net Creditors? Quarterly J Economics. 2013;128: 1321-64.

15. African Development Bank and GFI. Illicit Financial Flows and the Problem of Net Resource Transfers from Africa: 1980-2009. 2013 https://www. gfintegrity.org/storage/gfip/documents/reports/AfricaNetResources/gfi_ afdb_iffs_and_the_problem_of_net_resource_transfers_from_africa_1980-2 009-web.pdf. Accessed 9 July 2020.

16. World Bank. Domestic resource mobilization (DRM) and Illicit financial Flows (IFFs): board update. Washington, D.C.: World Bank Group; 2017. http:// documents.worldbank.org/curated/en/877291492623853466/DomesticResource-Mobilization-DRM-and-Illicit-Financial-Flows-IFFs-Board-Update. Accessed 9 July 2020.

17. O'Hare B, Makuta I, Bar-Zeev N, Chiwaula L, Cobham A. The effect of illicit financial flows on time to reach the fourth millennium development goal in sub-Saharan Africa: a quantitative analysis. J R Soc Med. 2014;107:148-56.

18. O'Hare B, Makuta I. An analysis of the potential for achieving the fourth millennium development goal in SSA with domestic resources. Glob Health. 2015;11:8.

19. Ortega B, Sanjuán J, Casquero A. Social costs of illicit financial flows in lowand middle-income countries: the case of infant vaccination coverage. Health Policy Plan. 2018:33:224-36.

20. International Monetary Fund. The role of the IMF in supporting the implementation of the post-2015 development agenda. Washington, DC: IMF; 2015.

21. World Bank. From billions to trillions: MDB contributions to financing for development. Washington (DC): World Bank; 2015.

22. United Nations. Financing for development: Progress and prospects. Report of the inter-agency task force on financing for development 2017. New York: United Nations; 2017.

23. Barroy H, Vaughan K, Tapsoba Y, Dale E, Van de Maele N. Towards Universal Health Coverage: Thinking Public. Overview of Trends in Public Expenditure on Health (2000-2014). World health organization. Health Financing Working Paper No 7; 2017

24. World Bank. World development report, 2017. Washington (DC): Governance and the Law; 2017.

25. Lustig N. Domestic resource mobilization and the poor. Governance and the Law; 2016.

26. OECD. Better Policies for Development 2014: Policy coherence and Illicit financial Flows. Paris: OECD; 2014. http://www.oecd.org/pcd/Better-Policiesfor-Development-2014.pdf. Accessed 9 July 2020.

27. OECD. Better policies for sustainable development 2016 - A new framework for policy coherence. Paris: OECD; 2016. https://sustainabledevelopment.un. org/content/documents/commitments/493_12066_commitment_BetterPolicies-for-Sustainable-Development-2016.pdf. Accessed 9 July 2020.

28. United Nations Office on Drugs and Crime (UNODC), Organisation for Economic Co-operation and Development. Coherent policies for combatting Illicit Financial Flows. Paris: OECD; 2016.

29. United Nations. A/RES/70/1. Transforming our World: the 2030 Agenda for Sustainable Development; 2015. https://sustainabledevelopment.un.org/ post2015/transformingourworld.

30. WHO. World Health Organization. World health statistics 2017: Monitoring health for the SDGs, sustainable development goals. Geneva: World Health Organization; 2017.

31. Ndikumana L, Boyce JK. Africa's odious debts: how foreign loans and capita flight bled a continent. London: Zed Books; 2011.

32. O'Hare B, Curtis M. Health spending, illicit financial flows and tax incentives in Malawi. Malawi Med J. 2014;26:133-7.

33. Mosselmans I. Tax evasion: the main cause of global poverty. (03/2014) at Resource document. http://blogs.Ise.ac.uk/africaatlse/2014/03/07/taxevasion-the-main-cause-of-global-poverty, 2014.

34. Schäferhoff M, Martínez S, Ogbuoji O, Sabin ML, Yamey G. Trends in global health financing. BMJ. 2019;365:12185. 
35. Janský P. Updating the rich countries' commitment to development index how they help poorer ones through curbing illicit financial flows. Soc Indic Res. 2015;124:43-65.

36. Ndikumana L, Boyce JK, Ndiaye AS. Capital flight from Africa: measurement \& drivers. In: I. Ajayi I, Ndikumana L, eds. Capital flight from Africa. Causes, effects, and policy issues (15-54). Oxford: Oxford University Press; 2015.

37. O'Hare B. Weak health systems and Ebola. Lancet. 2015;3:e71-2.

38. Rodriguez MA. Consequences of capital flight for Latin American debtor countries. In: Lessard DR, Williamson J, editors. Capital flight and third world debt (129-152). Washington (DC): Institute for International Economics; 1987.

39. Chipalkatti N, Rishi M. External debt and capital flight in the Indian economy. Oxf Dev Stud. 2001;29:31-44.

40. Ndikumana L, Boyce JK. Public debts and private assets: explaining capital flight from sub-Saharan African countries. World Dev. 2003;31:107-30.

41. Boyce J, Ndikumana L. Africa's debt: who owes whom? In: Epstein GA, editor. Capital flight and capital controls in developing countries (334-340). Cheltenham: Edward Elgar; 2005.

42. Cerra V, Rishi M, Saxena S. Robbing the Riches: Capital Flight, Institutions, and Instability. International Monetary Fund. Working Paper WP/05/199; 2005.

43. Beja E. Brothers in distress: revolving capital flows of Indonesia, Malaysia, and Thailand. J Asian Econ. 2007;18:904-14.

44. Abbott $P$, Sapsford R, Binagwaho A. Learning from success: how Rwanda achieved the millennium development goals for health. World Dev. 2017;92: 103-16.

45. Farag M, Nandakumar AK, Wallack SS, Gaumer G, Hodgkin D. Does funding from donors displace government spending for health in developing countries? Health Aff. 2009;28:1045-55.

46. Martínez Álvarez M, Borghi J, Acharya A, Vassall A. Is development assistance for health fungible? Findings from a mixed methods case study in Tanzania. Soc Sci Med. 2016;159:161-9.

47. Cardamone T. Addressing Illicit financial Flows in the FfD and SDG processes. Global Financial Integrity. 2015; http://www.gfintegrity.org/ addressing-illicit-financial-flows-in-the-financing-for-development-ffd-andsustainable-development-goal-sdg-processes/.

48. Forstater M. Illicit financial Flows, trade Misinvoicing, and multinational tax avoidance: the same or different? CGD policy paper. Washington, DC: Center for Global Development; 2018.

49. United Nations Conference on Trade and Development. Trade Misinvoicing in Primary Commodities in Developing Countries: The cases of Chile, Cote d'Ivoire, Nigeria, South Africa and Zambia. New York and Geneva, 2016.

50. High Level Panel on Illicit Financial Flows from Africa. Track it! Stop It! Get It! 2015.

51. Ritter I. Illicit financial Flows: an analysis and some initial policy proposals. Berlin: Friedrich-Ebert-Stiftung; 2015

52. Muldoon KA, Galway LP, Nakajima M, Kanters S, Hogg RS, Bendavid E, Mills EJ. Health system determinants of infant, child and maternal mortality: A cross-sectional study of UN member countries. Glob Health. 2011;7:42.

53. Babones S. Methods for quantitative macro-comparative research. New York: Sage; 2013

54. Reuter P. Illicit Financial Flows and Governance: The Importance of Disaggregation. Background paper for World Development Report 2017. Governance and the Law; 2017.

55. Hogan DR, Stevens GA, Hosseinpoor AR, Boerma T. Monitoring universal health coverage within the sustainable development goals: development and baseline data for an index of essential health services. Lancet Global Health. 2018;6:e152-68.

56. Kamal N, Curtis S, Hasan MS, Jamil K. Trends in equity in use of maternal health services in urban and rural Bangladesh. Int J Equity Health. 2016:15-27.

57. Angrist JD, Pischke JS. Mostly harmless econometrics: an Empiricist's companion. Ch. 3. Princeton: Princeton University Press; 2009.

58. Wooldridge JM. Econometric analysis of cross section and panel data. 2nd ed. London: The MIT Press: 2010.

59. Baum CF, Schaffer ME, Stillman S. Enhanced routines for instrumental variables/generalized method of moments estimation and testing. Stata J. 2007;7:465-506.

60. Stock J, Yogo M. Testing for weak instruments in linear IV regression. In: Andrews DWK, editor. Identification and inference for econometric models. New York: Cambridge University Press; 2005. p. 80-108.

61. United Nations. Financing for development: Progress and prospects. Report of the inter-agency task force on financing for development 2018. New York: United Nations; 2018.
62. Boerma T, Requejo J, Victora CG, et al. Countdown to 2030: tracking progress towards universal coverage for reproductive, maternal, newborn, and child health. Lancet. 2018;391:1538-48.

63. Shalev M. Limits and alternatives to multiple regression in comparative research. Comparative Social Research. 2007;24:261-308.

64. Lee K, Lush L, Walt G, Cleland J. Family planning policies and programmes in eight low-income countries: A comparative policy analysis. Soc Sci Med. 1998;47(7):949-59.

65. USAID. Family Planning and Reproductive Health Program Overview, 2017.

66. Black RE, Levin C, Walker N, Chou D, Liu L, Temmerman M. Reproductive, maternal, newborn, and child health: key messages from disease control priorities 3rd edition. Lancet. 2016;388:2811-24.

67. Canning D, Schultz TP. The economic consequences of reproductive health and family planning. Lancet. 2012;380:165-71.

68. Jamison DT, Summers LH, Alleyne G, et al. Global health 2035: A world converging within a generation. Lancet. 2013;382:1898-955.

69. Starrs AM, Ezeh AC, Barker G, et al. Accelerate progress-sexual and reproductive health and rights for all: report of the Guttmacher-lancet commission. Lancet. 2018;391:2642-92.

70. McGuire JW. Democracy, basic service utilization, and under-5 mortality: a cross-national study of developing states. World Dev. 2006;34:405-25.

71. World Health Organization (WHO). Immunization coverage. https://www. who.int/news-room/fact-sheets/detail/immunization-coverage. Accessed 9 July 2020

\section{Publisher's Note}

Springer Nature remains neutral with regard to jurisdictional claims in published maps and institutional affiliations.
Ready to submit your research? Choose BMC and benefit from:

- fast, convenient online submission

- thorough peer review by experienced researchers in your field

- rapid publication on acceptance

- support for research data, including large and complex data types

- gold Open Access which fosters wider collaboration and increased citations

- maximum visibility for your research: over $100 \mathrm{M}$ website views per year

At BMC, research is always in progress.

Learn more biomedcentral.com/submissions 